\title{
Physiological Correlates of the Precedence Effect and Summing Localization in the Inferior Colliculus of the Cat
}

\author{
Tom C. T. Yin \\ Department of Neurophysiology, University of Wisconsin, Madison, Wisconsin 53706 and Vision, Touch and Hearing \\ Research Centre, University of Queensland, St. Lucia, Queensland, Australia
}

\begin{abstract}
The precedence effect (PE) describes an illusion produced when two similar sounds are delivered in quick succession (interclick delays of 2-8 msec) from sound sources at different locations so that only a single sound is perceived. The localization of the perceived sound is dominated by the location of the leading sound. If the delays are very short (<1-2 msec), summing localization occurs and a phantom source is perceived whose location is toward the leading sound. The purpose of these experiments was to look for physiological correlates of the precedence effect and summing localization by recording from single neurons in the inferior colliculus of the anesthetized cat. Click stimuli were delivered under two different situations: over headphones in dichotic experiments and through two speakers in an anechoic room in free-field studies. In the latter case the cat was placed midway between the speakers and a single click stimulus was delivered to each speaker with variable interclick delays (ICDs). Most cells, under both dichotic and freefield conditions, exhibited a form of the precedence effect in which the response to the lagging click was suppressed when ICDs were short. The suppression of the lagging click, or echo, was measured by recovery curves, which plotted the response of the lagging click as a function of ICD. There was considerable variability in the recovery curves from different cells: the ICDs at which the recovery reached $50 \%$, which is a measure of the echo threshold for the cell, ranged from 1 to $100 \mathrm{msec}$ with a median of $20 \mathrm{msec}$. Human psychophysical experiments report echo thresholds for clicks ranging from 2 to $8 \mathrm{msec}$. If we assume that absolute echo threshold is determined by the cells with shortest recovery curves, then the thresholds for single cells are in accord with the psychophysical results. The possible sites of generation
\end{abstract}

Received Nov. 9, 1993; revised Jan. 31, 1994; accepted Feb. 24, 1994.

I thank Jack Pettigrew, Director of the Vision, Touch and Hearing Research Centre at the University of Queensland, and the rest of the staff of VTHRC, too numerous to enumerate, for use of the facilities, support, assistance, and stimulating discussions. Special thanks to Danny Thomas, who provided invaluable assistance with computer matters. Thanks to a number of people who participated in these experiments at one time or another: Laurel Carney, Janine Clarey, Philip Joris, Ken McAnally, Tosaku Nikara, Indira Raman, and Eric Young. Laurel Carney, Philip Joris, Ruth Litovsky, and Luis Populin provided helpful comments to an earlier version of the manuscript. Finally, I thank the staff of the Department of Neurophysiology for their usual expert assistance: Carol Dizack, JoAnn Ekleberry, Robert Klipstein, Ravi Kochhar, Joan Meister, Inge Siggelkow, and Terry Stewart. This work was supported by Grant DC00116 from NIDCD and Grant TW01653 from the NIH Fogarty International Center.

Correspondence should be addressed to Tom C. T. Yin, Department of Neurophysiology, 273 Medical Science Building, University of Wisconsin Medical School, Madison, WI 53706.

Copyright (C) 1994 Society for Neuroscience $0270-6474 / 94 / 145170-17 \$ 05.00 / 0$ of the echo suppression are also considered. Changes in the relative level of the leading and lagging clicks produced the expected shifts in the recovery curves. With short ICDs in the summing localization range (between about $\pm 2 \mathrm{msec}$ ), cells also showed responses consonant with the human psychophysical result that the sound source is localized to a phantom image between the two speakers and toward the leading one. The location of the image varied systematically with the relative levels or ICDs of the clicks. These results suggest that the neural substrate for many of the psychophysical effects of the PE and summing localization are seen at the level of the ICC and therefore lend support to the two basic assumptions: that the cat also experiences the PE and that the discharge of at least some cells in the ICC is related to the perceived location of the sound source.

[Key words: precedence, summing localization, inferior colliculus, sound localization, echo suppression]

When two similar sounds from different locations are delivered in quick succession, a single sound is perceived whose location is dominated by the location of the leading sound. This effect, usually called the "precedence effect" (PE), "law of the first wavefront," or "Haas effect," is believed to be responsible for our ability to localize sounds accurately despite the presence of many echoes in our normally reverberant environment (Hartmann, 1983). This illusion is a compelling one and can be easily demonstrated in the free field with ordinary stereophonic equipment or with dichotic stimulation over earphones by adjustment of the interaural time differences (ITDs) of transient stimuli (Wallach et al., 1949; Haas, 1951).

In psychoacoustic studies of the PE in free field, a subject is usually placed midway between two speakers while a transient stimulus (e.g., a click) is delivered to each speaker with variable interclick delay (ICD) (Fig. 1A). Three time periods have been identified based upon judgements of the perceived location of the stimulus as a function of ICD (Fig. 1B). Echo threshold is the ICD at which an observer hears both clicks at their respective locations. The value of the echo threshold varies considerably with the stimulus, from about $2-8 \mathrm{msec}$ for clicks to $30 \mathrm{msec}$ for speech (Blauert, 1983). Below this threshold, a single click is perceived, which is localized either to the leading speaker during the precedence effect $(1<|\mathrm{ICD}|<5 \mathrm{msec})$, or to a phantom source whose location is toward the leading speaker during summing localization when $|\mathrm{ICD}|<1 \mathrm{msec}$. When the two clicks are delivered simultaneously $(\mathrm{ICD}=0)$, the phantom source will appear to be on the midline directly in front of the subject. During the period of the PE, or echo suppression, the suppression of the lagging click is similar to a forward masking 
effect by the leading sound, whereas during summing localization there is a backward effect in which the lagging sound influences the response to the leading one. It is important to note that during the PE the lagging click is not truly suppressed, since its presence affects the timbre and loudness of the perceived sound as well as its spatial extent (Blauert, 1983; Perrott et al., 1987, 1989; Litovsky and MacMillan, 1993).

The PE has also been studied dichotically over headphones using stimuli that attempt to mimic the free-field situation $(\mathrm{Zu}-$ rek, 1987). Usually this has been done by delivering two pairs of dichotic clicks with different ITDs (Fig. 1C). The first dichotic pair with ITD1 is meant to simulate the leading click while the second pair with ITD2 simulates the echo. Psychoacoustic studies have shown that information about ITD2 is suppressed during the PE period (Zurek, 1980; Gaskell, 1983; Yost and Soderquist, 1984; Lindemann, 1986; Blauert and Divenyi, 1988; Saberi and Perrott, 1990) and that ITD2 can influence judgements of lateral position during summing localization (ShinnCunningham et al., 1993).

Before looking for the physiological substrate for a psychophysical effect, it is necessary to consider whether the phenomenon is also experienced by animals. A number of behavioral studies suggest that at least some of the psychophysical effects of the PE are likely to be present in cats. These studies (Cranford et al., 1971; Whitfield et al., 1972; Cranford and Oberholtzer, 1976) have shown that normal cats can locate the leading sound under free-field conditions with interstimulus delays of 3-16 msec and that this ability is disrupted in the hemifield contralateral to a lesion of the auditory cortex. However, these experiments do not show that the location of the lagging sound is suppressed nor do they demonstrate summing localization, as described in human psychophysical studies. Cranford (1982) studied the effect of varying ICD after cats had been trained to approach the leading sound source, and found that optimal performance in cats was obtained for ICDs of $0.5-2.0 \mathrm{msec}$. Interestingly, all cats performed near $50 \%$ for ICD $=0 \mathrm{msec}$, suggesting that they exhibited summing localization and heard the phantom source between the two speakers. Similar behavioral studies have also demonstrated echo suppression in the rat (Kelly, 1974) and cricket (Wyttenbach and Hoy, 1993). Despite the lack of compelling evidence for the precedence effect and summing localization in the cat, I will nonetheless assume for the purposes of interpreting the physiological results that the cat experiences both effects in a manner similar to that characterized in human psychophysical studies.

This article describes physiological recordings in cells in the central nucleus of the inferior colliculus (ICC) using stimuli that are expected to evoke the PE and summing localization. I chose the ICC because in previous experiments using ITDs of click stimuli, both forward and backward masking effects were seen (Carney and Yin, 1989). With only a single click to each ear and long ITDs, the response to the lagging click was suppressed in most cells, sometimes over tens of milliseconds, even when the leading click was not effective in eliciting a response. In addition, a click lagging up to $1 \mathrm{msec}$ in one ear could suppress the response to the leading click delivered to the other ear, illustrating a possible backward masking effect. Carney and Yin (1989) speculated that the long-lasting suppression was effective for echo suppression while the shorter backward effect was important for sound localization and could be used for summing localization. To test this hypothesis, in the present experiments I recorded from cells in the ICC using stimuli that were expected
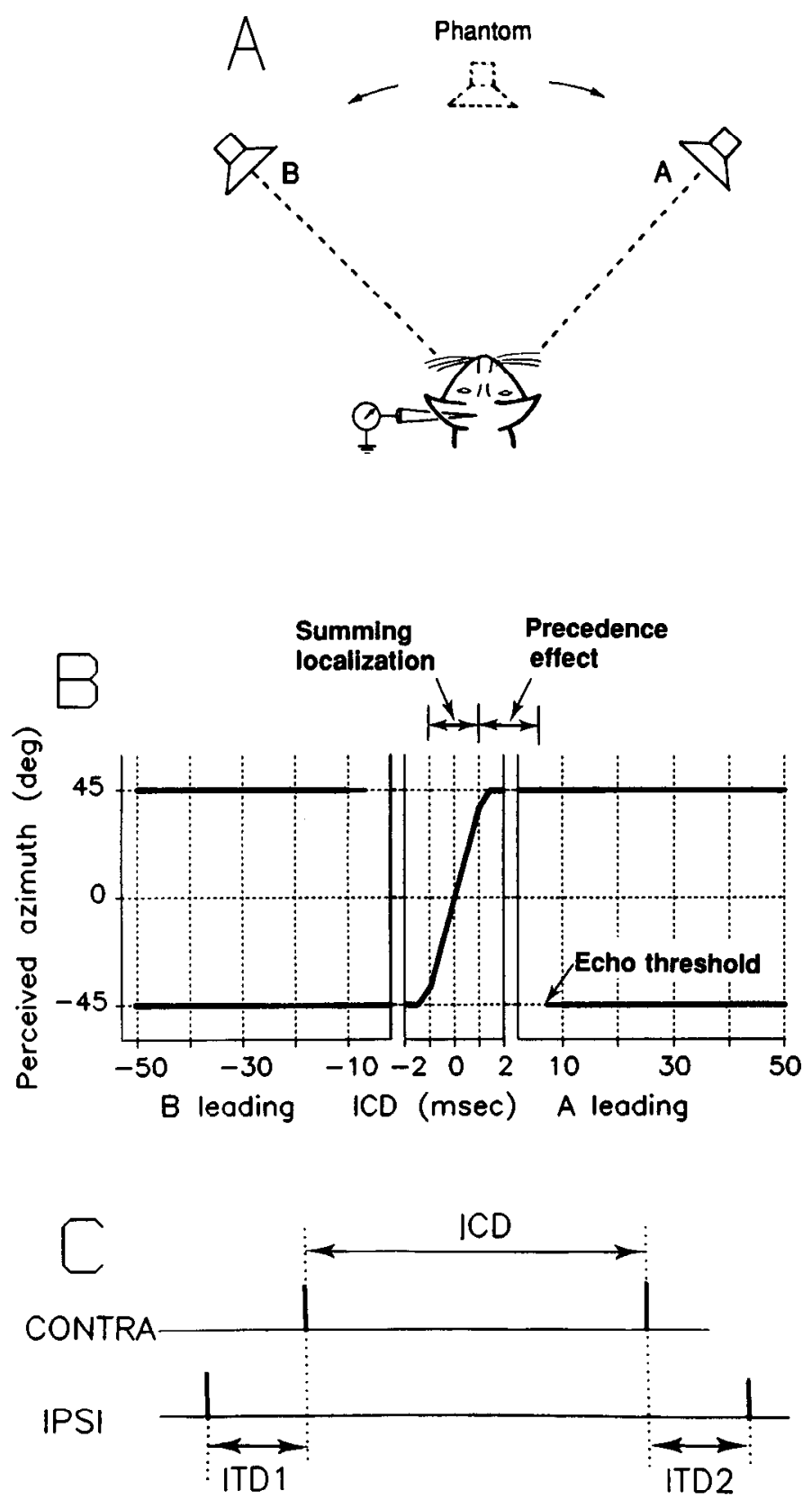

Figure 1. Stimulus configurations in free-field $(A)$ and dichotic conditions $(C)$, and general psychophysical effects $(B)$ of the PE and summing localization. $A$, A cat is positioned midway between two speakers that are located at $0^{\circ}$ elevation and $\pm 45^{\circ}$ azimuth. Two clicks, one from each speaker, are delivered with variable interclick delay (ICD). By convention negative ICDs correspond to delays of the click to speaker $A$ in the contralateral sound field relative to the recording microelectrode shown on the left side. $B$, The perceived location of the clicks, as derived from results of psychophysical experiments in humans. Three time periods have been identified: summing localization, precedence effect, and ICDs greater than echo threshold. $C$, Dichotic stimulus configuration. Two pairs of clicks, separated by an ICD, are delivered with ITD1 in the conditioner, or leading pair, and ITD2 in the probe, or lagging pair.

to produce the PE and summing localization using both freefield and dichotic stimulation conditions. Many studies have shown that ICC cells are sensitive to the two prominent binaural cues used for sound localization, ITDs and interaural level differences (Rose et al., 1966; Kuwada and Yin, 1983; Yin et al., 1986; Semple and Kitzes, 1987; Carney and Yin, 1989; Irvine 
and Gago, 1990), and there are data from free-field studies suggesting that the ICC contains a topographic representation of space (Aitkin et al., 1985). Two fundamental assumptions implicit in this experiment arc that the discharge of the cclls in the ICC is related to the perceived location of the sound source in space and that the cat experiences the PE and summing localization in the same manner as human subjects.

\section{Materials and Methods}

The dichotic experiments were done at the University of Wisconsin while the free-field experiments were performed in the Vision, Touch and Hearing Research Centre at the University of Queensland while I was on sabbatical leave. Similar experimental procedures were used in both sets of experiments whenever possible.

Surgery. The general experimental methods have been described in detail previously (Yin et al., 1986, 1987; Carney and Yin, 1989). Adult cats with clean external ears and no sign of middle ear infection were induced with sodium pentobarbital given intraperitoneally $(35 \mathrm{mg} / \mathrm{kg})$. A venous cannula was inserted in the femoral vein and additional intravenous doses of sodium pentobarbital were given as needed to maintain areftexia. A tracheal cannula was inserted and rectal temperature was maintained near $37^{\circ} \mathrm{C}$ with a heating pad.

The dorsal surface of the inferior colliculus (IC) was exposed by aspirating the overlying cerebral cortex. In some cases the tentorium was also removed to permit access to more of the IC. Parylene-coated tungsten microelectrodes (Microprobe, Clarksburg, MD) with tip exposures of 12-15 $\mu \mathrm{m}$ were aimed at the IC. Warmed agar was dripped over the surface of the IC after the electrode was in position. Conventional techniques were used to record the extracellular action potentials from single cells. Typically, in the dorsalmost $1 \mathrm{~mm}$ or so the cells in the pericentral nucleus of the $\mathrm{IC}$ were broadly tuned to high characteristic frequencies (CFs). As the electrode continued ventrally, the CFs dropped rapidly to very low frequencies $(<400 \mathrm{~Hz})$ and then gradually increased. The dorsal boundary of the ICC was identified as the point at which the first low $\mathrm{CF}$ cells were encountered. A hydraulic microdrive was used to control the movement of the microelectrode remotely from outside the soundproof room in the dichotic experiments, while a manual microdrive was used in the free-field studies. Single spikes were discriminated using a level discriminator in conjunction with a peak-detector circuit so that the pulses to the computer event timer occurred at the peak of the spike.

Free-field experiments. The free-field experiments in Queensland used a large $(3.6 \times 2.9 \times 2.6 \mathrm{~m})$ soundproof room whose inner walls were lined with specially made absorbent foam of $40 \mathrm{~cm}$ thickness. The surgical procedure was as described above except as follows. After induction of anesthesia, the cat's head was placed in the standard stereotaxic position. The skin overlying the skull was cut along the midline and a craniotomy was made in the skull over the ICC. In addition, a stainless steel rod, placed in a horizontal position behind the head and aligned along the long axis of the brainstem, was then anchored to the skull using dental acrylic and three or four small screws into the bone. After aspirating the visual cortex and exposing the dorsal surface of the IC, the skin was resutured so that the external ears assumed a natural, upright position with the constraint that the craniotomy was still accessible.

After the surgery was completed, the cat was taken out of the stereotaxic frame and placed in the anechoic chamber. The cat's head was supported with the steel rod, which was anchored to a frame in the chamber, and its body was supported by a canvas hammock, which included a warm water heating pad for maintaining body temperature. The cat's head was positioned in the center of an imaginary sphere of $160 \mathrm{~cm}$ diameter defined by the movement of a speaker (Motorola piezo tweeter) whose position could be moved under computer control along the surface of the sphere. Although the speaker could be placed virtually anywhere around the cat, only positions in the frontal hemifield along the horizontal meridian $\left(0^{\circ}\right.$ elevation) were explored in this experiment. The position directly in front of the cat was defined as $0^{\circ}$ azimuth, $0^{\circ}$ elevation, and positive azimuths were in the contralateral and negative azimuths in the ipsilateral sound field. The CFs of the cells were estimated by finding the frequency with the lowest threshold to tonal stimuli at the spatial position, usually in the contralateral sound field, that evoked the maximal response.

To mimic echoes emanating from a different direction, a second identical speaker, which $I$ will refer to as the B speaker, was also placed in the ipsilateral sound field at $\left(-45^{\circ}, 0^{\circ}\right)$, while the movable A speaker was placed at $\left(+45^{\circ}, 0^{\circ}\right)$. A single click was delivered to each speaker with variable interclick delays (ICDs). To accommodate movement of the hoop, the stationary ipsilateral speaker was placed outside the arc of the movable hoop, and was thus $20-23 \mathrm{~cm}$ farther away from the cat. Therefore, when the stimuli were delivered simultaneously, the ipsilateral sound was delayed by $600-700 \mu \mathrm{sec}$ and attenuated by about $2 \mathrm{~dB}$ in relation to the movable speaker. The additional delay, but not the attenuation, of the ipsilateral speaker has been taken into account in all of the specified values of ICDs and levels. Clicks of $100 \mu \mathrm{sec}$ duration were delivered with a repetition interval of 200 or $500 \mathrm{msec}$ and repeated 50 times.

Dichotic experiments. Both external ears were removed and the external auditory meatuses were cut transversely to allow insertion of tightfitting hollow earpieces, through which the acoustic stimuli were delivered. The earpieces were aimed at the malleus and sealed into the ear canals with Audalin ear impression compound. A small hole was drilled into the wall of each bulla and a polyethylene tube of $\sim 0.9 \mathrm{~mm}$ i.d. and $60 \mathrm{~cm}$ length was inserted into the hole and sealed with glue to maintain the middle ear pressure. The animal was placed in a double-walled, sound-insulated, and electrically shielded room (IAC). Acoustic stimuli were generated by the digital stimulus system and delivered by a pair of Telex 140 speakers coupled to the earpieces with Tygon tubing. Each ear was calibrated by delivering tones hetween 0.1 and $43 \mathrm{kHz}$ and recording with a 0.5 inch Bruel and Kjaer condenser microphone that sampled the acoustic waveform via a probe tube near the eardrum. A wide array of digital stimuli could be delivered dichotically. Generally the $\mathrm{CF}$ of the cell was determined using contralateral tonal stimulation. All tonal stimuli in dichotic experiments were compensated using the acoustic calibration and expressed in sound pressure level (SPL re 20 $\mu \mathrm{Pa}$ ). Stimuli with different spatial positions in free field were simulated by imposing ITDs between the clicks to the two ears. Thus, the precedence stimulus was simulated by delivering a pair of clicks to each ear separated by an ICD with an ITDI in the leading click pair and an ITD2 in the lagging click pair (Fig. 1C). The ICD was defined as the interval between the clicks to the contralateral ear; positive ITDs refer to interaural time delays of the ipsilateral stimulus. Thus, in Figure $1 C$, ITD1 is negative while ITD2 is positive. Initially, the sensitivity of the cell to variations in ITDs with a single click pair was determined in order to select the optimal ITD.

Stimuli for studying precedence and summing localization. To compare the suppressive effect in different cells, two standard stimulus configurations were employed, one for free-field and one for the dichotic experiments. Since it is difficult to measure suppression of a weak response, the lagging click was chosen to be at a position (or to have an ITD) that evoked a strong response, which for most cells in the ICC means a point in the contralateral field (or with a positive ITD). Because the suppression also appeared more potent when the leading click evoked a strong response (see below), in dichotic experiments the leading click pair was chosen to have the same ITD as the lagging click pair with the aim of measuring the maximal suppressive effect, though it simulates the unnatural situation of having the leading sound and echo originate from the same location. In free field, it was not possible for technical reasons to have both the leading and lagging click emanate from the same speaker, so the leading click was chosen to be placed in a mirrorimage position in the ipsilateral field, simulating the usual psychophysical configuration (Fig. 1A). These two standard configurations are not readily comparable since the leading clicks evoked different responses in the dichotic and free-field conditions.

In choosing the level of the clicks to use in studying the PE, two opposing factors were considered. Since the spatial position of a source in free field can produce relatively large changes in the level of the stimulus to one ear, relatively high click levels are needed to ensure that the cells were being stimulated binaurally. On the other hand, low click levels are needed to keep the ICC cells from saturating in their rate/ level responses (Carney and Yin, 1989). In balancing these two factors, I usually used click levels in free field that were about $20 \mathrm{~dB}$ above the cell's threshold at the optimal position. Since no changes in level with variations in ITD were introduced in dichotic experiments, lower click levels could be used, usually about $10 \mathrm{~dB}$ above threshold at the optimal ITD. Levels of the clicks were referenced to the maximum attenuation possible, which was $100 \mathrm{~dB}$ in free-field and $127 \mathrm{~dB}$ in dichotic experiments. Therefore, a level of $25 \mathrm{~dB}$ indicates $75 \mathrm{~dB}$ attenuation of the maximum signal in free-field and $102 \mathrm{~dB}$ attenuation in dichotic experiments. 

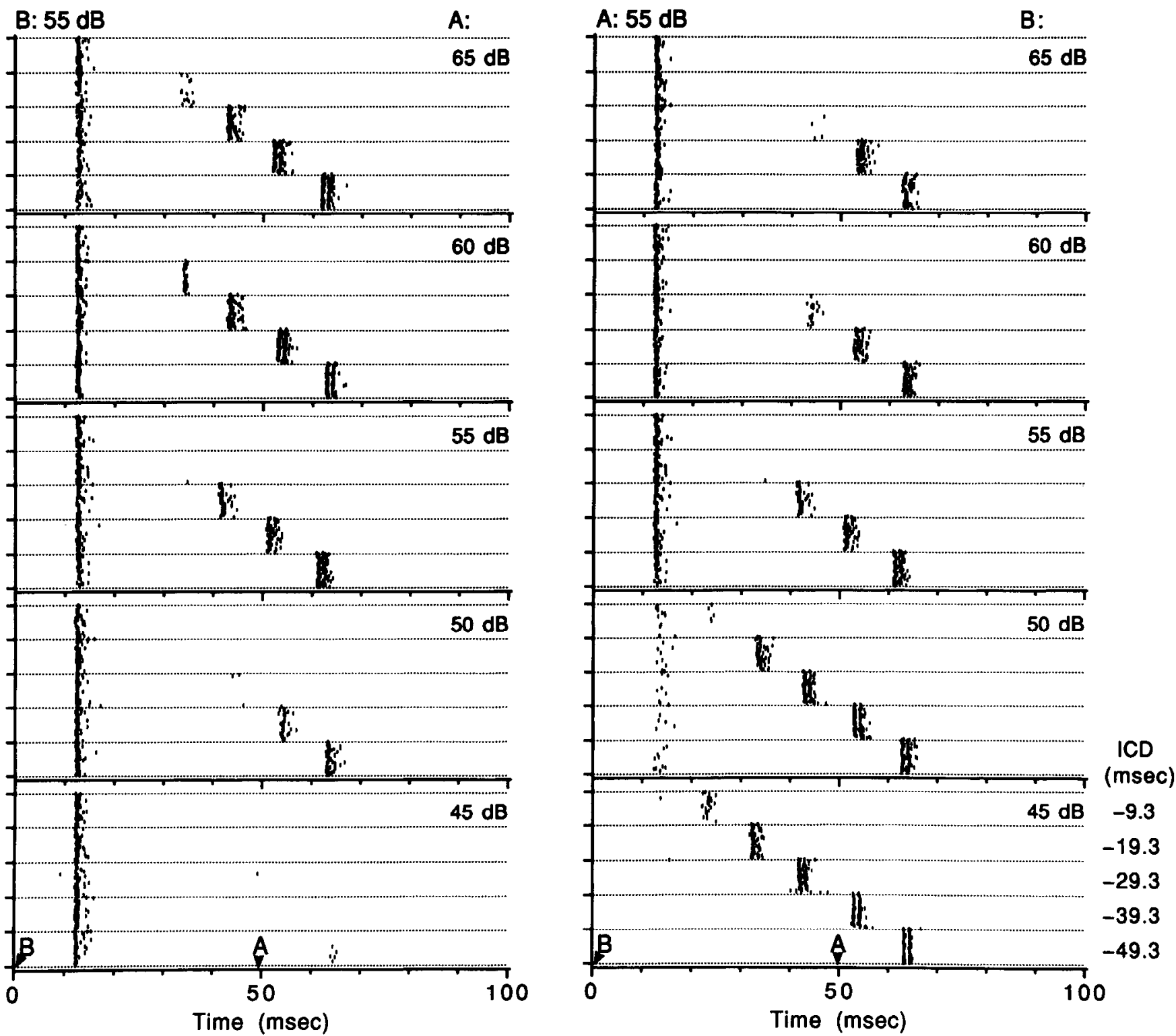

Figure 2. Effect of varying ICD and level on echo suppression to click pairs delivered in free field. Each set of five dot rasters represents the responses to click B at time 0 while click A was delayed by the value of ICD from 9.3 to $49.3 \mathrm{msec}$. In the left column, the level of click B was held constant at $55 \mathrm{~dB}$, while the level of $\mathrm{A}$ varied from $65 \mathrm{~dB}($ top $)$ to $45 \mathrm{~dB}$ (bottom). In the right column, A was held constant at $55 \mathrm{~dB}$ while the level of $\mathrm{B}$ was varied. $\mathrm{CF}=1.7 \mathrm{kHz}$.

\section{Results}

Data base

These data were obtained from studies of 80 neurons (from 17 cats), 35 of which were studied under free-field conditions in an anechoic room and the remainder under dichotic conditions. Only cells that responded to the $100 \mu \mathrm{sec}$ clicks were studied; 30 other cells were encountered that could not be driven by these standard clicks. Most of the cells unresponsive to clicks had long-latency (usually 30-80 $\mathrm{msec}$ ) responses to tones and noise or had very low CFs, below the range of the free-field transducers, which had limited low-frequency responses. Most $(88 \%, 70$ of 80$)$ of the recordings were from the low-frequency cells with $\mathrm{CF}<4 \mathrm{kHz}$, but a few high-frequency cells were also studied for comparison. There were no obvious differences in the responses to the PE and summing localization stimuli in the low- and high-frequency cells.

\section{Echo suppression and the precedence effect}

The effects of varying ICD and the relative level of the leading and lagging clicks are shown in Figure 2. Each set of five dot rasters shows responses from a cell in the ICC to the standard free-field stimuli in which the click (A) from the contralateral hemifield was delayed from 9.3 to $49.3 \mathrm{msec}$. This cell responded to clicks delivered from either sound field, though it was more sensitive to contralateral stimulation. In every case there was more suppression of the response to the lagging A click as the ICDs were shortened. In addition, the strength of this suppression depended upon the relative levels of the two clicks: it was longer-lasting when the level of the lagging click was decreased (left column, top to bottom) or when the level of the leading click was increased (right column, bottom to top). Similar effects of changing the relative levels of the leading and lagging clicks were seen in the other 10 cells in which such 

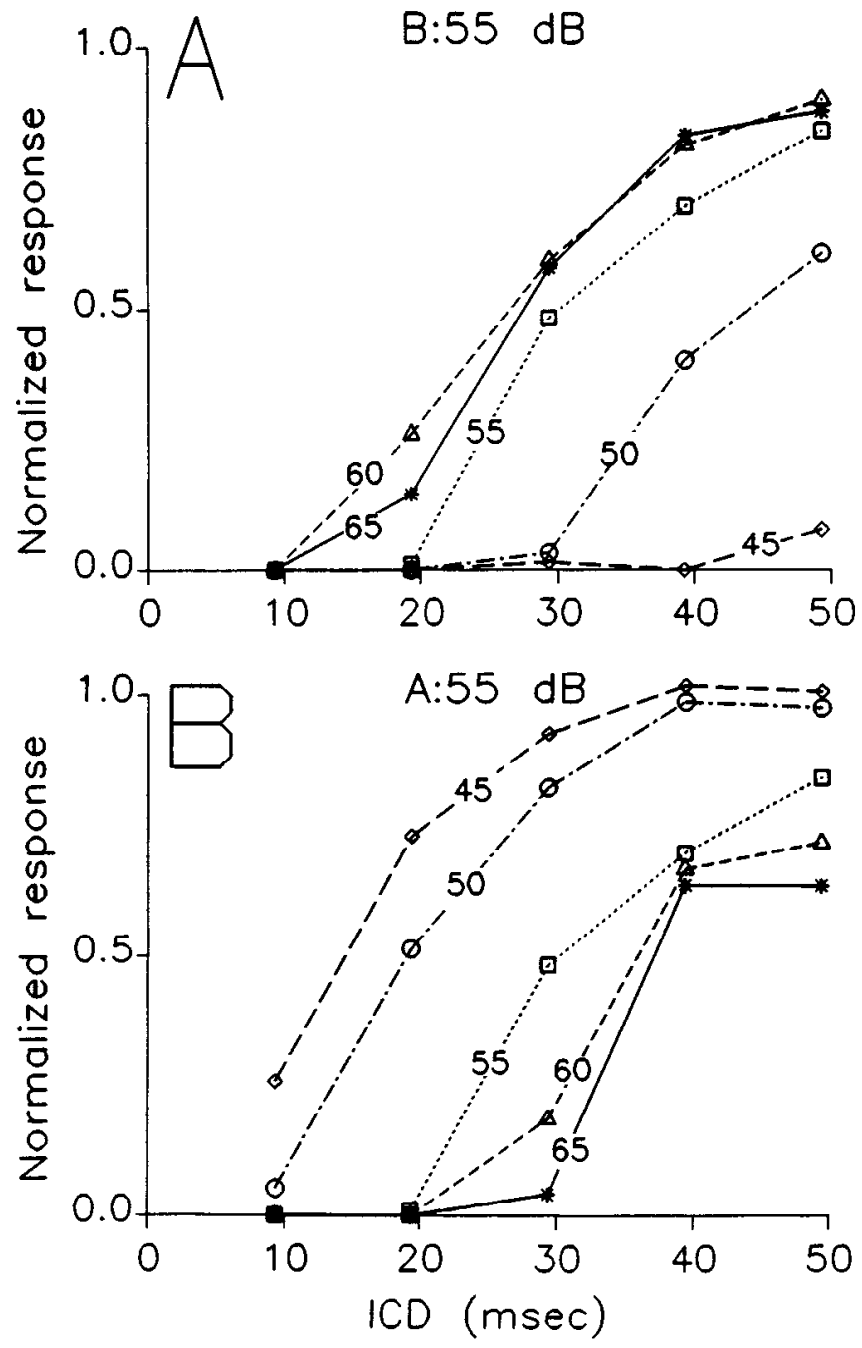

Figure 3. Suppression of the lagging A click as a function of ICD for the free-field data of Figure 2. A, Click $B$ was held at $55 \mathrm{~dB}$ while $A$ varied from 45 to $65 \mathrm{~dB}$. These responses correspond to the left column of Figure 2. B, Click A was held at $55 \mathrm{~dB}$ while B varied from 45 to 65 $\mathrm{dB}$, corresponding to the right column of Figure 2. In both plots the responses to the lagging click are normalized to that obtained to a single A click at the same level: in $B$ all responses were divided by 97 spikes/ 50 trials, while in $A$ they were divided by $65,92,97,104$, and 110 for $45,50,55,60$, and $65 \mathrm{~dB}$, respectively.

manipulations were studied. Note that there was suppression at an ICD $=-9.3 \mathrm{msec}$ even if the leading click was below threshold and too weak to elicit a response (Fig. 2, bottom of right column).

To discriminate responses to the leading and lagging clicks at any given ICD, the ICD must be longer than the duration of the response. For most cells, this requirement was upheld since the responses to the clicks were transient with distinct onsets and offsets and/or there was no response to the lagging click at short ICDs. To quantify the echo suppression, the responses were analyzed by counting spikes within discrete time windows. For the response to the leading click the window was chosen based upon the latency and duration of the response; the same analysis window was used for the lagging click except that the ICD was added to the latency. In three cells, either the response duration was too long or the suppression too weak so that the leading and lagging time windows overlapped at short ICDs; in such cases the analysis was done only for those ICDs for which there was no overlap.

When the responses in Figure 2 to the lagging $\mathrm{A}$ click are plotted as a function of ICD in Figure 3, the systematic change in suppression with relative level is evident. In Figure 3 the responses were normalized by dividing the response to $A$ when preceded by $B$ by the response to a single click to speaker $A$ at the corresponding level. Such echo suppression functions can also be regarded as forward masking recovery curves, for they show the degree of suppression of the response to the lagging click by virtue of the presence of the leading one. I will also refer to the leading click as the conditioner and the lagging one as the probe, in accordance with common usage in masking experiments. To quantify the degree of suppression as a function of ICD, the point at which the response to the probe was $50 \%$ of the response to a single click at $\mathrm{A}$ was determined by linear interpolation between points. In Figure 3 this half-maximal delay was $30 \mathrm{msec}$ with clicks of $55 \mathrm{~dB}$. It varied from 14 to 37 msec as $B$ increased from 45 to $65 \mathrm{~dB}$ and from 26 to $44 \mathrm{msec}$ as $A$ decreased from 65 to $50 \mathrm{~dB}$; the half-maximal delay was larger than $50 \mathrm{msec}$ when $A$ was $45 \mathrm{~dB}$.

Similar results in terms of echo suppression were also seen in the dichotic experiments. The standard stimulus configuration was obtained with both ITD1 and ITD2 set to the value that elicited a maximal response, simulating two clicks coming from the same location in space. Figure $4 A$ shows the response of a cell to precedence stimuli in which the ICD was varied from 1 to $101 \mathrm{msec}$. There was a strong suppression of the response to the probe, which was complete for ICDs of $<6 \mathrm{msec}$. Figure $4 B$ shows the recovery curve for this response. It was computed in an analogous fashion as for the free-field responses illustrated in Figure 3, except that the response to the probe was normalized by the response to the conditioner, since the leading and lagging clicks have the same ITD. As was the case for freefield responses, there was considerable variability in the suppression in different cells. Half-maximal delay for this cell was 12 msec.

Figure 5 shows samples of recovery curves, which were chosen to illustrate the range of suppressions seen under free-field (Fig. $5 A$ ) and dichotic (Fig. $5 C$ ) conditions. Figure $5 A$ shows responses for 12 ICC cells obtained with the standard free-field clicks, while Figure $5 B$ shows a histogram of the half-maximal ICDs for 29 cells. In all cases the responses were normalized to the response obtained from a single click to the contralateral speaker and half-maximal ICDs were computed from linear interpolation. The half-maximal ICD for two cells was less than $2 \mathrm{msec}$, but could not be measured because of overlap between the leading and lagging analysis windows, while for the 29 cells of Figure $5 B$ it ranged from 1.0 to 90 msce with a mcan of 25.4 $\mathrm{msec}$; the median of the entire population was $20 \mathrm{msec}$. Figure $5 C$ shows a sample of recovery curves for 13 cells, and Figure $5 D$, the histogram of half-maximal ICDs obtained under the standard dichotic condition. These curves were normalized by dividing the lagging response by the leading one. One cell's halfmaximal ICD was too short to measure, while for the 36 cells of Figure $5 D$, it ranged from 1.5 to $100 \mathrm{msec}$ with a mean of $31.5 \mathrm{msec}$ and a median for all cells of $20 \mathrm{msec}$. A striking aspect of both sets of data in Figure 5 was the large variability in the half-maximal ICDs.

During the dichotic experiments in 11 cells, I also tested for echo suppression under monaural stimulation conditions. In 
these cases either the ipsilateral or the contralateral stimulus was turned off. For all cells, echo suppression was also seen under monaural conditions and the recovery curve was similar to that seen under binaural stimulation. In three of these cells both monaural ipsilateral and monaural contralateral conditions were tested with similar results. In one cell the suppression evoked by monaural stimulation to one ear on the response to monaural stimulation of the opposite ear was also comparable to that evoked under binaural conditions. While these results must be considered preliminary, they nonetheless suggest that the suppression can usually be evoked by monaural as well as binaural stimuli.

\section{Summing localization}

Free field. The suppression of a lagging stimulus by the presence of a leading one is a common attribute in the CNS and is not limited to the auditory system, or to situations where an "echo" is suppressed. More interesting is the possibility of any backward effect, as during summing localization, that is, of the lagging stimulus influencing the response to the leading one. Again, in the absence of compelling behavioral data in the cat, I am assuming that it also experiences summing localization in a similar fashion as do human subjects.

Let us begin by considering what the behavior of cells would be if they exhibited the PE and summing localization. To do this, it is necessary to know the azimuthal sensitivity of the cell. Figure 6 shows predicted responses of two cells with different azimuthal receptive fields using the same stimulus configuration as Figure $1 A$ and assuming that the discharge of these cells reflects the cat's perceived location of the stimulus. In Figure $6 A$ the hypothetical cell does not respond to stimuli in the ipsilateral field and has a peak response at the location of speaker A. When two clicks are delivered with variable ICD, the predicted response of a cell that exhibits precedence is shown in Figure $6 \mathrm{~B}$. When the click to speaker $\mathrm{B}$ leads by more than 50 msec, the cell should "hear" both clicks, but since it does not respond to stimuli in the ipsilateral sound field, the response will be only to the delayed click from A. As the ICD is shortened toward the echo threshold, the response to $A$ will gradually be suppressed until it completely disappears when $B$ leads by less than the echo threshold, or about $10 \mathrm{msec}$. As the ICD is increased from -1 to $+1 \mathrm{msec}$, the perceived location of the stimulus moves from speaker $B$ to speaker $A$, that is, from $-45^{\circ}$ to $+45^{\circ}$. If the response of the cell mirrors this perceived change in location, then the azimuthal response from $-45^{\circ}$ to $+45^{\circ}$ should be mapped onto the ICD function from -1 to $+1 \mathrm{msec}$, as illustrated in Figure $6 B$. With $\mathrm{ICD}>+1 \mathrm{msec}$, the response should be to the leading $A$ speaker with no further changes as ICD is progressively increased since there is no response to $B$.

The response of a cell with such an azimuthal receptive field studied in free field is shown in Figure 7. The dot rasters in Figure $7 C$ show that when ICD $=-99.3 \mathrm{msec}$ with click B leading, there was no response to $B$ and a vigorous response to A. As the ICD was made less negative, the delayed response to A was gradually suppressed, even though click B did not evoke a response, until there was no response to $A$ near ICD $=-1$ msec. As the ICD became positive and click $A$ led, there was a gradual recovery of the response to $A$ but never any response to the delayed B click. Note that for $0<\mathrm{ICD}<2 \mathrm{msec}$, in which click $A$ leads by a short ICD, the response is considerably weaker than that obtained with click A by itself, which shows
A

ICD

ITD $1=400 \mu \mathrm{sec} ; \quad$ TTD2 $=400$ usec (msecs)

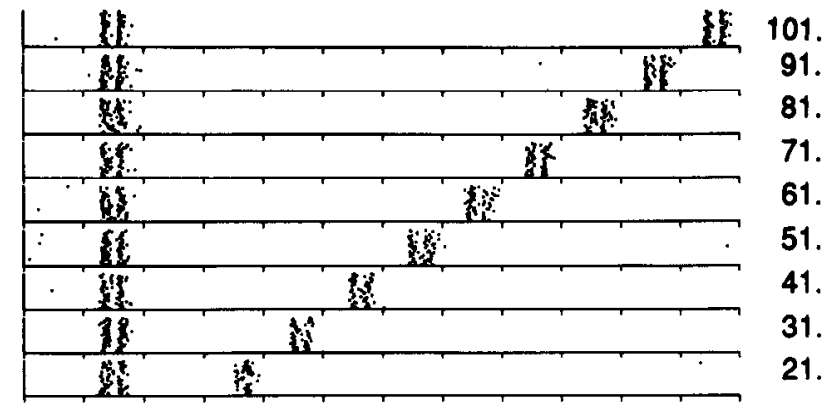

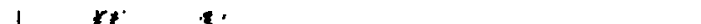

\begin{tabular}{|ll}
1 & 16 \\
\hline & 15 \\
\hline & 14
\end{tabular}

13.

12.

11.

10.

9.

8.

7.

6.

5.

4.

3.

2.

1.

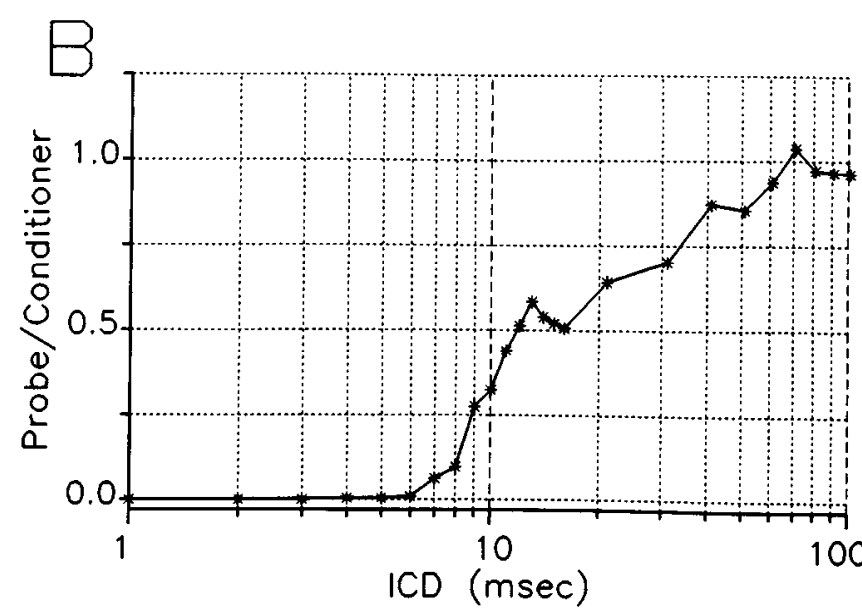

Figure 4. Echo suppression studied under dichotic stimulation. A, Dot rasters showing the responses of a cell to ICDs ranging from 1 (bottom) to 101 (top) msec in which both ITDl and ITD2 were set to $400 \mu \mathrm{sec}$. Each stimulus was repeated 40 times with a repetition interval of 200 msec. $B$, Recovery curve for the responses in $A$. A time window of (12, 19) msec was used to count the spikes in response to the conditioner, while a window of (ICD + 12, ICD + 19) msec was used for the probe. Half-maximal delay was $12.0 \mathrm{msec} . \mathrm{CF}=0.4 \mathrm{kHz}$. 

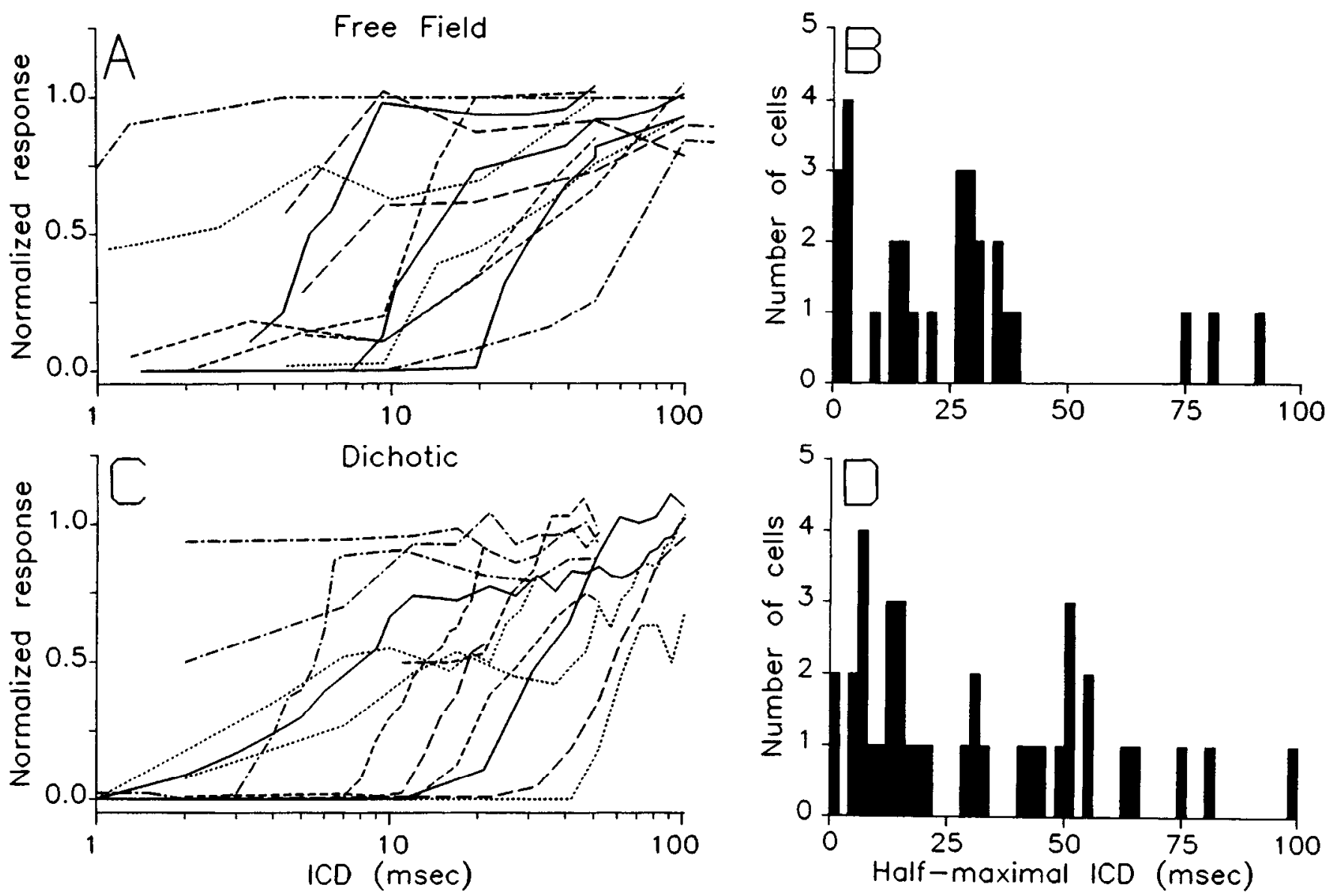

Figure 5. Sample suppression functions $(A, C)$ and histograms $(B, D)$ of half-maximal ICDs for free-field $(A, B)$ and dichotic $(C, D)$ conditions. $A$, Echo suppression in the standard free-field configuration for a representative sample of 12 cells. The responses to the lagging click are normalized by the response to a single A click at the same level. $B$, Histogram of half-maximal ICDs for 29 cells measured in free field. $C$, Echo suppression in the standard dichotic configuration for a sample of 13 cells. Responses are normalized by the response to the leading click. $D$, Histogram of half-maximal ICDs for 36 cells measured with dichotic stimulation.

the suppression elicited by the presence of the lagging B click. In terms of summing localization, it appears that the closely following click from B pulls the perceived image away from A toward the midline, where the cell's receptive field shows a weak response (Fig. $7 A$ ). The plot of discharge as a function of ICD in Figure $7 B$ is similar to that predicted in Figure $6 B$. The transition in response from -2 to $+2 \mathrm{msec}$ is what would be expected for summing localization, as the image moves from point $\mathrm{B}$ to $\mathrm{A}$ on the azimuthal sensitivity curve (Fig. $7 \mathrm{~A}$ ).

Figure 8 shows another example of a cell studied in free field with a similar receptive field except that it also responded, though more weakly, to stimuli in the ipsilateral hemifield. In this case at large negative ICDs there was an onset response to $B$ (plotted separately by the dashed line in Fig. $8 B$ ) followed by the response to $A$, which was near the level in Figure $8 A$ without a preceding stimulus. As the ICD was made less negative, there was a gradual suppression of the response to $A$ until the suppression was complete when A was delayed by less than $19 \mathrm{msec}$. As ICD was increased through the summing localization range from -1 to $+1 \mathrm{msec}$, there was gradual recovery of the response until it reached the same level as that produced by $A$ alone. The suppressive effects of the clicks at $\mathrm{A}$ and $\mathrm{B}$ differed considerably: there was complete suppression of A only when B led by $<20$ msec with virtually no suppression at $-99 \mathrm{msec}$, yet there was complete suppression of B even with ICD of $100 \mathrm{msec}$.
A more stringent test of our hypothesis is provided by the azimuthal receptive field shown in Figure $6 C$ in which there is a maximum between points $A$ and $B$ and $a$ response in the ipsilateral sound field. The response predicted for the hypothetical cell that exhibits the PE and summing localization is shown in Figure $6 D$. When ICD $=-50 \mathrm{msec}$, both clicks will evoke a response equal to that seen in the receptive field: an onset response to B of 25 spikes and a delayed response to $A$ of 75 spikes. As the ICD becomes less negative, the delayed response to $A$ is gradually suppressed, until at ICD $=-10 \mathrm{msec}$ only the onset response is seen. As in the case for Figure 6, $A$ and $B$, the azimuthal receptive field between $-45^{\circ}$ and $+45^{\circ}$ should be mapped to ICDs from -1 to $+1 \mathrm{msec}$. Since the azimuthal receptive field passes through a peak, the hypothesis makes the strong prediction that the ICD function will also have a peak of 100 spikes between 0 and $+1 \mathrm{msec}$. From +1 to +10 msec, only speaker A is heard. As ICD is increased beyond the echo threshold, the response consists of an onset response to $A$ of 75 spikes and a gradual recovery of the delayed response to $B$, eventually reaching 25 spikes at the largest ICD.

Free-field responses from a cell with a receptive field similar to that of Figure $6 \mathrm{C}$ are shown in Figure 9. The cell responded to both clicks $A$ and $B$ and there was a maximum between points $A$ and $B$ through which the response to the phantom source would be expected to pass. When ICD $=-100 \mathrm{msec}$ with $\mathrm{B}$ 

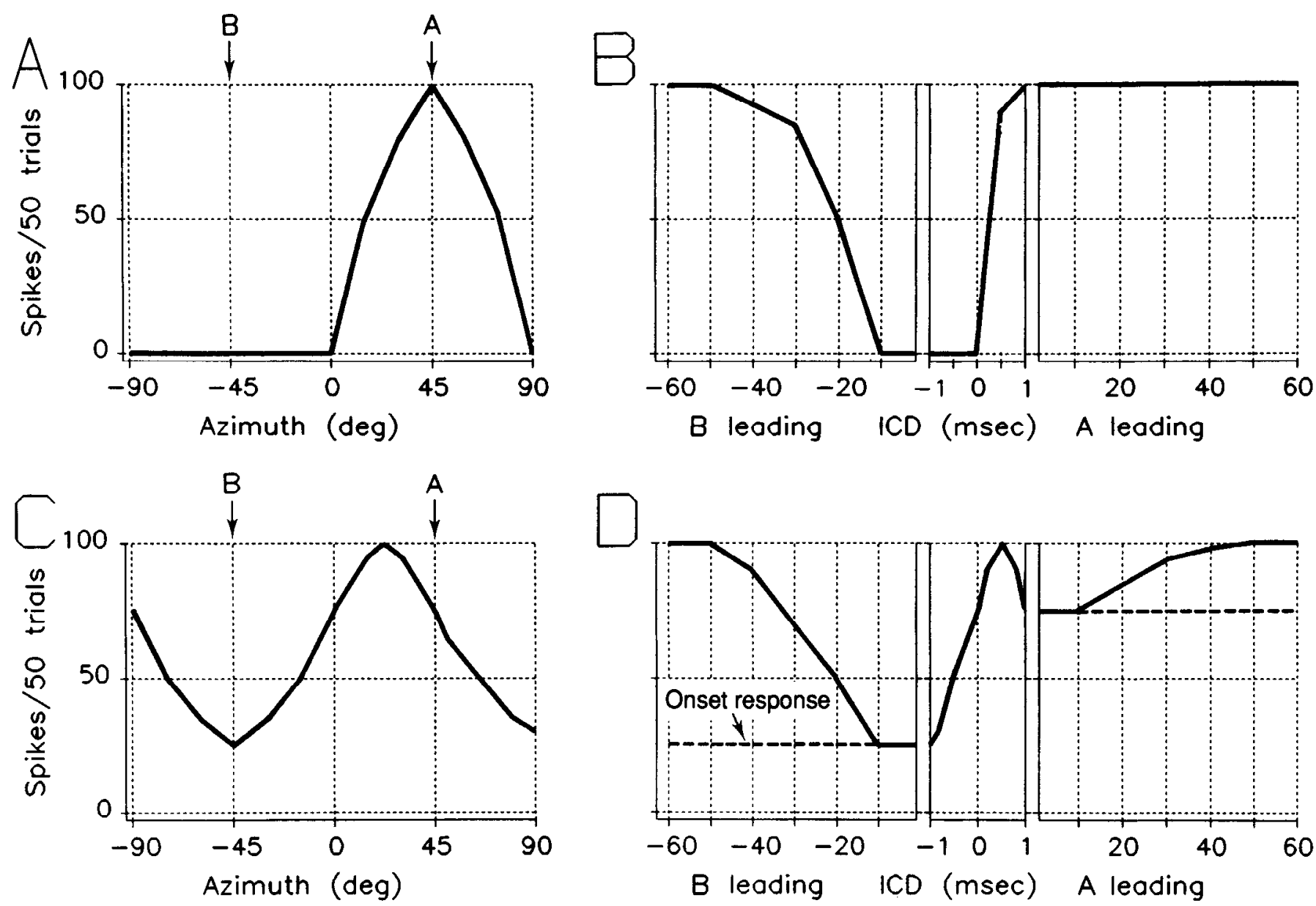

Figure 6. Predictcd responses of two hypothetical cells with different azimuthal receptive field profiles $(A, C)$ that exhibit the precedence effect to variations in ICD $(B, D)$. In $A$ and $B$ are responses of a cell with a simple receptive field profile, whereas in $C$ and $D$ are responses of a cell with a more complex receptive field.

leading, there was a weak onset response to $B$ and a stronger delayed response to $\mathrm{A}$ as expected from the receptive field (Fig. $9 A)$. As ICD was made less negative, the onset response remained unchanged but there was a gradual, though incomplete, suppression of the response to the delayed click $A$. As the ICD was changed from -1 to $+1 \mathrm{msec}$, the response reached a maximum near ICD $=0 \mathrm{msec}$ and then fell somewhat at $+1 \mathrm{msec}$. This peak in the response was more apparent in the spike counts (Fig. $9 B$ ) than in the dot rasters (Fig. 9C). For ICDs $>50 \mathrm{msec}$ the response was primarily to the leading $A$ click while the response to the delayed $B$ click was suppressed with a slight recovery at $\mathrm{ICD}=+100 \mathrm{msec}$. To differentiate the responses to $\mathrm{A}$ and $\mathrm{B}$, the dotted curve in Figure $9 B$ plots separately the spikes evoked in the onset interval, in this case from 12 to 18 msec. The predicted (Fig. 6D) and the actual responses (Fig. 9B) were similar except that there was less suppression of the lagging A click than predicted. Note that the asymmetric receptive field profile of Figure $9 A$ with a peak at $0^{\circ}$ and a stronger response in the contralateral field was also reflected in the ICD function with an asymmetric peak at $0 \mathrm{msec}$ and a stronger response for positive ICDs.

Inspection of the responses at long negative ICDs in Figures 7-9 reinforces the observations presented earlier in studies of echo suppression recovery curves that the degree of suppression varies considerably from cell to cell. Figure 10 shows free-field responses from a cell with a strong suppressive effect even when the response to the conditioning click is completely ineffective. The receptive field profile (Fig. 10A) shows no response to click $\mathrm{B}$ but a robust response to click $\mathrm{A}$. The latter, however, can be totally inhibited when B leads by less than 9 msec. This suppression in the absence of responses to the leading click demonstrates that the effect is not due to fatigue or refractoriness of the ICC cell. For ICDs in the summing localization range, the response shows a peak near $0.7 \mathrm{msec}$, similar to that shown in Figure 9, which matches the peak in the response to contralateral azimuths (Fig. 10A). In this case the peak in the ICD curve is a bit higher than expected from the azimuth receptive field.

If the perceived location of the sound source during the summing localization period is reflected in the discharge of the cell as a function of ICD, then we expect the shape of the receptive field from $-45^{\circ}$ to $+45^{\circ}$ to be mapped onto the ICD function from -1 to $+1 \mathrm{msec}$. For all four of the examples shown above and for most, but not all, of the other cells that were studied, the receptive field profiles and ICD functions were similar within these limits. Deviations in the responses as a function of ICD from the response predicted from the receptive fields in some cells suggested that the response to short ICDs reflected a higher perceived level of the phantom click, for example, Figure $10 B$.

Dichotic. Similar effects were also seen with dichotic stimulation. In these experiments two pairs of dichotic clicks with 


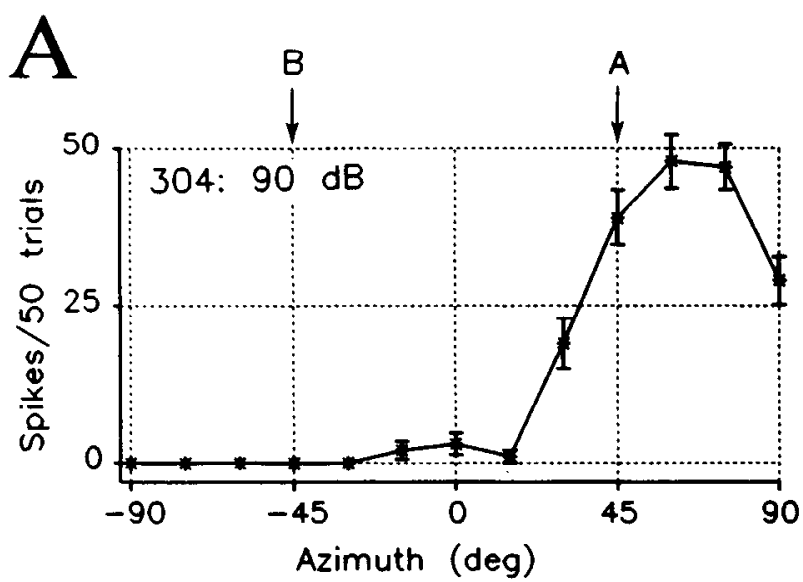

$\mathrm{B}$

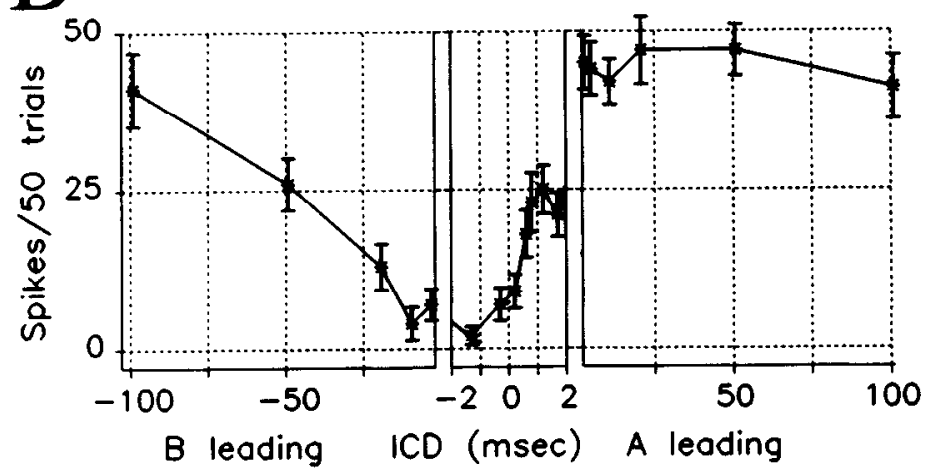

C

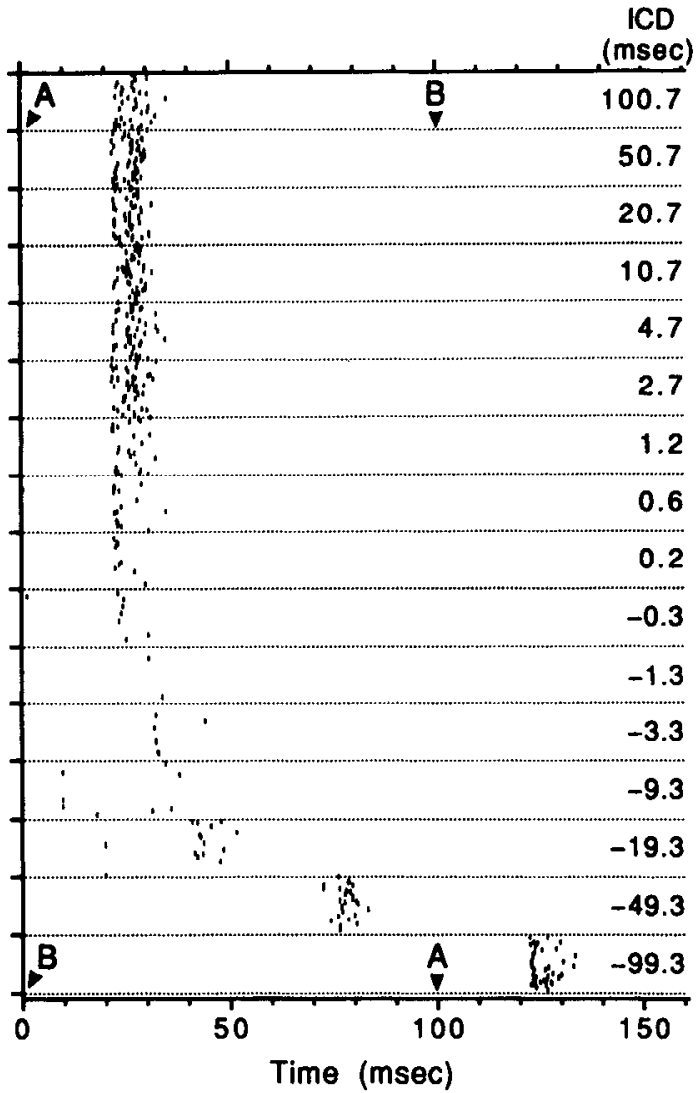

Figure 7. Responses of a cell with a simple receptive field to single clicks as a function of azimuth $(A)$ and double clicks as a function of ICD $(B$, $C)$ in the free field. In $B$ the total number of spikes, summed over the leading and lagging time windows, is plotted as a function of $1 C D$. $C F=$ $2.4 \mathrm{kHz}$. Error bars in $B$ represent \pm 1 SEM over 50 repetitions. In $C$ the same responses are plotted as dot rasters. Arrows labeled $A$ and $B$ indicate the time that speakers A and B were activated for the two longest ICDs. The same format holds for Figures 8-11.

opposite ITDs, rather than two clicks with different spatial positions, were delivered (Fig. 1C). The sensitivity of the cell to ITDs was first determined by single clicks to each ear (Fig. 11A); the cell responded maximally at ITD $=+200 \mu \mathrm{sec}$ and minimally at ITD $=-200 \mu \mathrm{sec}$, designated $\mathrm{ITD}_{\mathrm{A}}$ and $\mathrm{ITD}_{\mathrm{B}}$, or just $A$ and $B$, respectively. The responses to precedence-like stimuli with variations in ICD are shown in Figure $11, B$ and $C$. At ICD $=-31 \mathrm{msec}$, there was a weak response to the leading $\operatorname{ITD}_{B}$ followed by a stronger response to the lagging $\operatorname{ITD}_{A}$. The latter was gradually suppressed as ICD was shortened, though in this cell it was never completely suppressed. When ICD = $+31 \mathrm{msec}$, the weak response to $B$ was completely suppressed and only the onset response to A was seen. Of particular interest were the responses seen at ICD $= \pm 1 \mathrm{msec}$. At ICD $=-1 \mathrm{msec}$, the response was larger than that expected from the summation of the weak onset response to $B$ and the suppressed response to $A$; that is, there was a release of the suppression of $A$ by $B$ even though B still led by $1 \mathrm{msec}$. If interpreted in terms of the psychoacoustic effect, the lagging A click, which was at a favorable ITD, pulled the perceived source toward A, and thereby increased the discharge rate. Likewise, when $I C D=+1 \mathrm{msec}$, the response was considerably weaker than that obtained to $\mathrm{A}$ without a closely lagging $B$. Now, the presence of an unfavorable lagging $\operatorname{ITD}_{\mathrm{B}}$ decreased the responsc to the favorablc ITD $_{\mathrm{A}}$. In each case the responses were consistent with summing localization in that over short ICDs, the response to the click complex was weakened when the lagging click was at an unfavorable ITD and strengthened when it was at a favorable one. In terms of perceived ITD, it was as if the presence of the closely following click pulled the perceived location of the click complex to a point between $\mathrm{A}$ and $\mathrm{B}$, near the midline.

For the examples shown in Figures 7-11 the degree of suppression of the lagging sound appeared to depend upon the location or ITD of the leading sound, for example, the complete suppression of the response to B by A at $+20.7 \mathrm{msec}$ in Figure $8 C$ while there was only about $50 \%$ suppression of $A$ by $B$ at $-19.3 \mathrm{msec}$. Such comparisons, however, are not definitive, since both the lead and the lag are different and possibly one or the other is more difficult to suppress. To address this problem more systematically, it is necessary to keep the lagging sound constant and vary the location or ITD of the leading one.

Such an experiment is shown in Figure 12, under dichotic conditions. This cell responded well for positive ITDs, representing delays of the ipsilateral ear. ITD2 was set constant at $+200 \mu \mathrm{sec}$ while ITD1 varied over $\pm 400 \mu \mathrm{sec}$. The dot rasters of Figure $12 \mathrm{~A}$ show the expected azimuthal sensitivity in the responses to the leading clicks, which occur with a latency of about $10-13 \mathrm{msec}$, with a weak response to negative ITDs and a robust response to positive ones. When the ICD $=30 \mathrm{msec}$, there was no sign of suppression in the response to the lagging click, which occurred at $40-43 \mathrm{msec}$. At ICD $=10 \mathrm{msec}$, however, there was complete suppression of the lagging click when ITD1 was positive and weaker suppression when ITD1 was negative. By ICD $=2 \mathrm{msec}$, the suppression was complete. The 


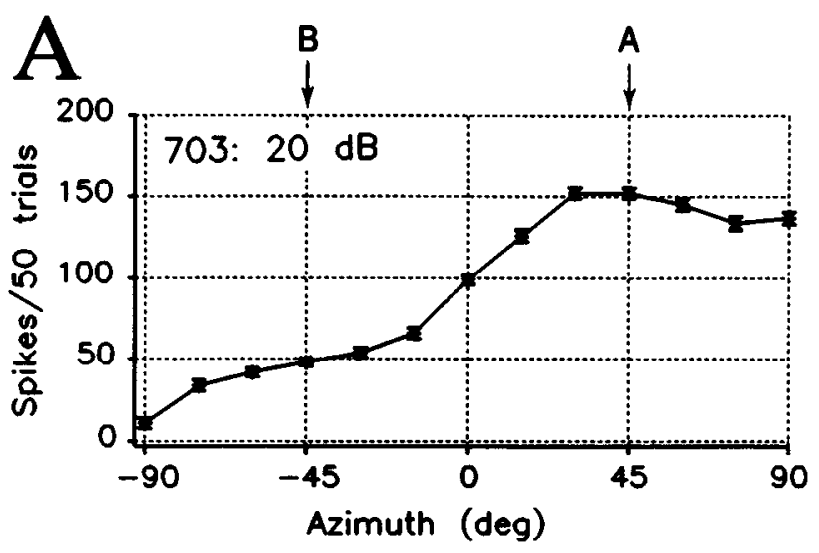

B

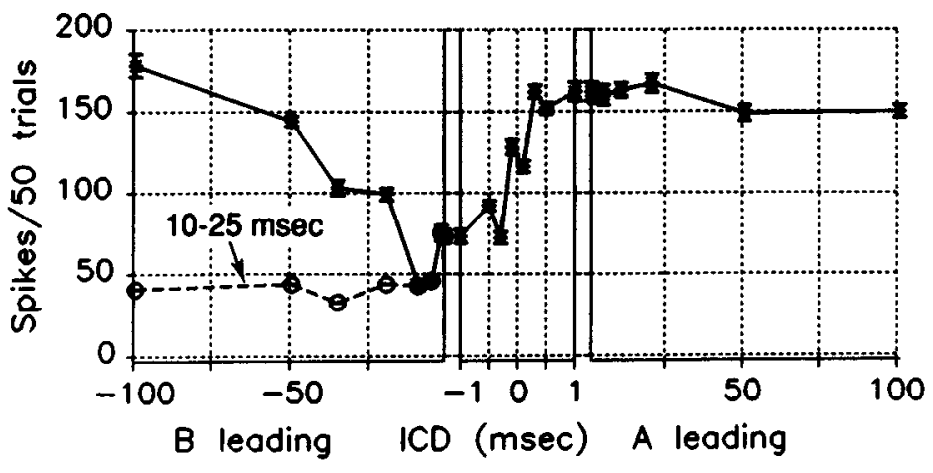

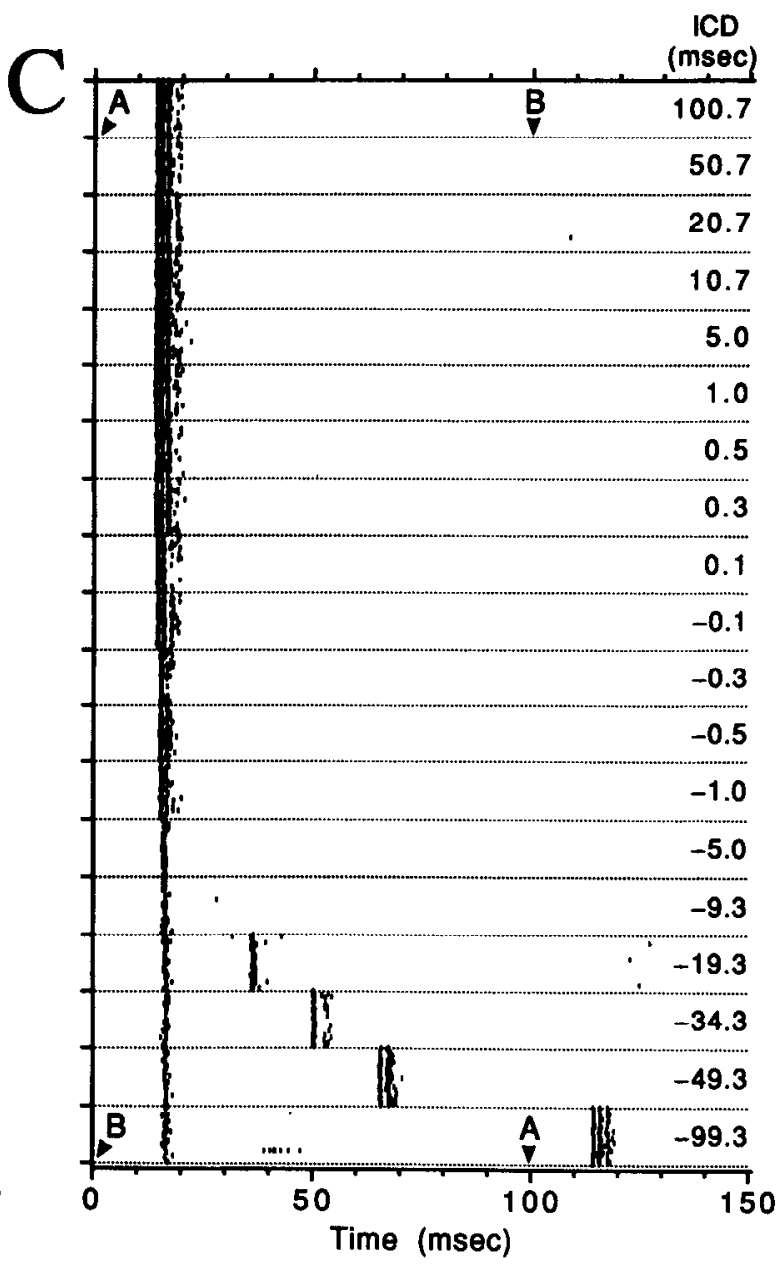

ICD

(msec)

Figure 8. Responses of a cell to single clicks as a function of azimuth $(A)$ and double clicks as a function of ICD $(B, C)$ in the free field. The number of spikes in the onset time interval during negative ICDs is indicated by the dashed line. $\mathrm{CF}=3.5 \mathrm{kHz}$.

responses in Figure $12 \mathrm{~A}$ show a strong dependency of the suppression on the ITD of the leading click pair: the suppression was strongest when the leading click pair had an ITD that evoked the strongest response.

Close examination of the response to the leading click shows an interesting effect: at the shortest ICD used, $2 \mathrm{msec}$, the response to negative ICDs was slightly greater than that seen for long ICDs, as shown in Figure $12 B$, which plots the number of spikes in the time window of $(9,15)$ msec. I interpret this increase in the response to be the beginning of a summing localization response in which the presence of a favorable lagging ITD elicited a stronger response to the leading click.

\section{Time/intensity trading}

Psychophysical experiments on summing localization in free field indicate that it is possible to move the perceived image from one side to another by varying either the ICD or the relative levels of the sound to the two speakers (Snow, 1954). Indeed, one can compensate for a time lag introduced to one speaker by increasing the level of the sound to that speaker. Figure 13 shows a physiological analog of such time/intensity trading in the free field. The receptive field of the cell is shown in Figure $13 A$ for a $20 \mathrm{~dB}$ signal, while responses to stimuli in the summing localization range are shown in Figure $13 B$. Consider first the response to varying ICDs when the $B$ speaker was at $23 \mathrm{~dB}$. At
ICDs near $0 \mathrm{msec}$, the response was a little more than 50 spikes (Fig. 13B), which was comparable to that when the speaker was straight ahead in the single click condition (Fig. 13A). When the level to the B speaker was raised to $33 \mathrm{~dB}$, the response dropped, as would be expected if the image were to move toward $-45^{\circ}$. This decrease in the response could be offset by giving the $A$ speaker a lead of about $0.5 \mathrm{msec}$. Similarly, by decreasing the level of the $B$ speaker to $18 \mathrm{~dB}$, there was an increase in the response which would correspond to a movement of the perceived image toward $+45^{\circ}$. This could also be offset by giving the B speaker a lead of about 0.5 msec. Thus, this cell shows a form of time/intensity trade that is similar to that described in psychophysical experiments.

\section{Discussion}

These data provide the first electrophysiological studies in the central auditory system using stimuli that are expected to produce the PE and summing localization. The results suggest that the neural substrate for many of the psychophysical effects of the PE and summing localization are seen at the level of the ICC. At least some cells in the ICC exhibit both the summing localization and echo suppressive effects described by psychophysical experiments. Variations in the relative level of the leading and lagging clicks produce changes in the cell's echo threshold. An important corollary of these results is the implication 


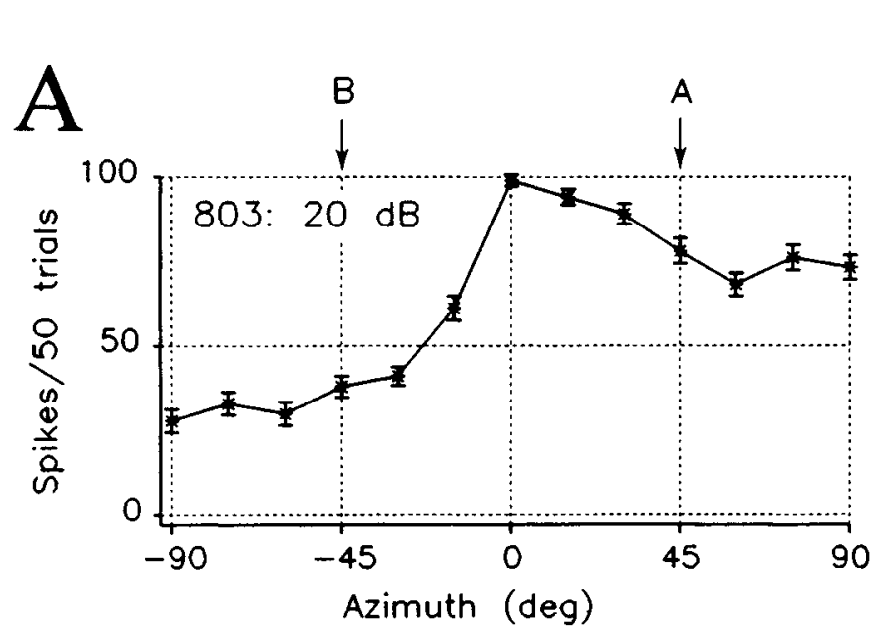

$\mathrm{B}$
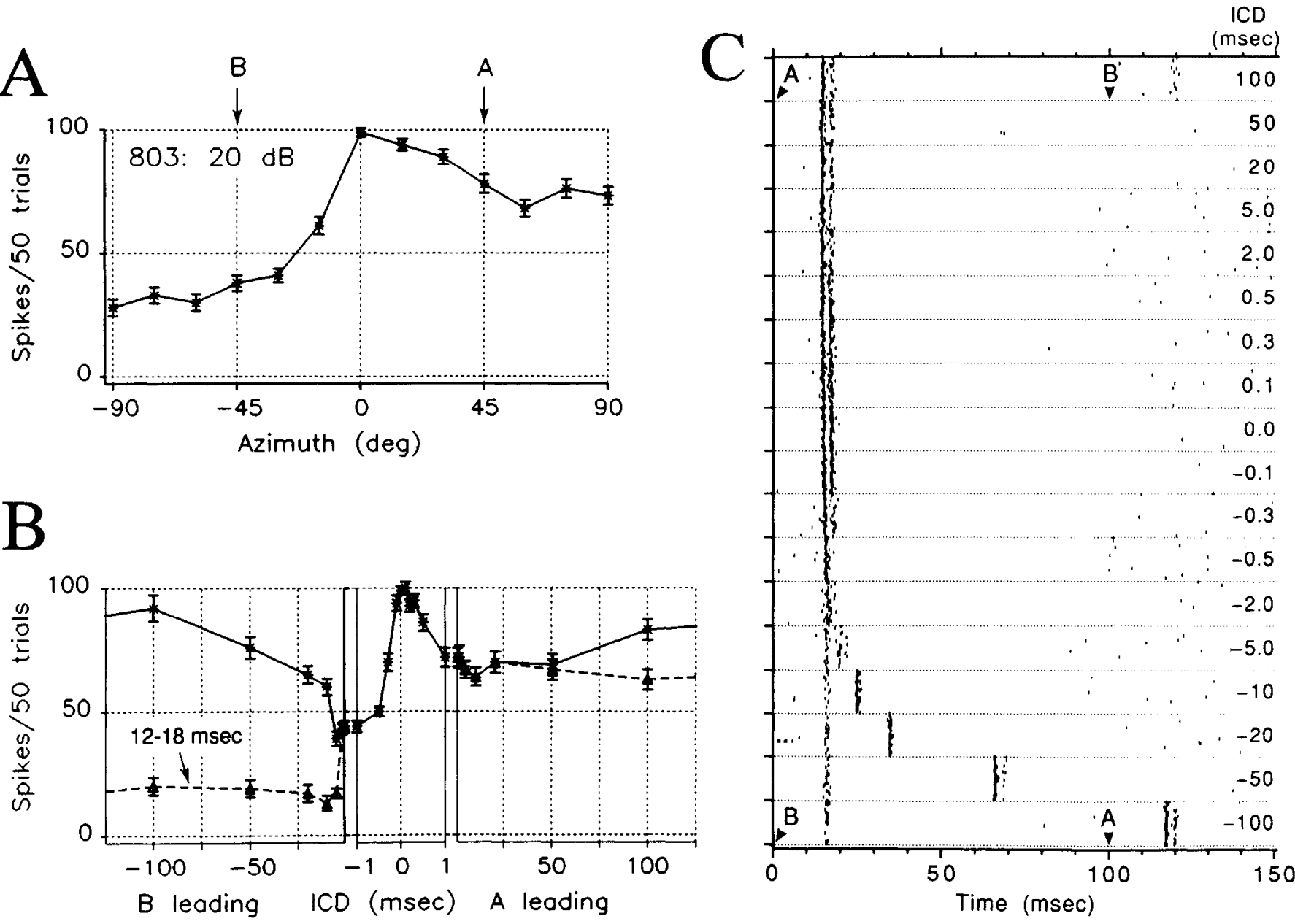

Figure 9. Responses to single clicks as a function of azimuth $(A)$ and double clicks as a function of ICD $(B, C)$ in the free field. The receptive field of this cell is more complex in that it responds to all stimuli with the peak response near $0^{\circ}$. CF $=0.8 \mathrm{kHz}$.

that the discharge of at least some cells in the ICC is related to the perceived location of the sound source. I will divide the following discussion into two general topics: the functional implications of these results for the psychophysical phenomenon of precedence and the neural mechanisms for generating these results.

\section{Functional implications for precedence}

An important question that immediately arises from a consideration of these results is to what extent the activity described here is related to the psychophysical phenomenon of precedence. I will argue below that many of the characteristics seen in the ICC in physiological responses to PE stimuli are consistent with the psychophysical effects, including the time course of echo suppression, the mapping of azimuthal sensitivity onto ICDs during summing localization, the effects of changing relative level of the lead and lag for echo suppression, the time/intensity trading for summing localization, and the occurrence of echo suppression for monaural and mixed monaural stimuli. Nonetheless, it is not possible to establish a causal relationship between the physiology and psychophysics; the most that can be said is that there is a tight correlation between the two. Physiological experiments in behaving animals will be needed to establish a closer link.

Echo suppression. The suppression of the lagging sound by the presence of a leading one seen in these physiological results mirrors the psychophysical characteristics of echo suppression in a number of ways. First, the time course of the suppression for the overall population of cells was similar to the behavioral results. Generally, measurements of echo suppression for click stimuli show considerable intersubject variability and range from 2 to $8 \mathrm{msec}$ (Blauert, 1983), depending upon a number of experimental factors: the sound level, the instructions given to the subject, and the positions of the sources. Echo thresholds depend strongly on the type of stimulus, being shortest for clicks and considerably longer for tones, noise, or speech (Blauert, 1983). Under headphones the echo threshold is usually less than in free field (Green, 1976). In our sample, there was considerable variability in the half-maximal delay from cell to cell. In general, the half-maximal ICD ranged from 1.5 to $100 \mathrm{msec}$ with a median of $20 \mathrm{msec}$ in both dichotic and free-field experiments (Fig. 5). In $4 \%$ of cells ( 3 of 68 ) the half-maximal ICD could not be measured because it was too short relative to the duration of the response, or too weak. It is, of course, difficult to relate psychophysical measurements of echo threshold with physiological suppression of single cells, even if the measurements are in the same animal, which is not the case here. An analogous situation is the comparison of behavioral detection of pure tones and the physiological thresholds of auditory nerve fibers: while the single fiber thresholds vary considerably, the behavioral 

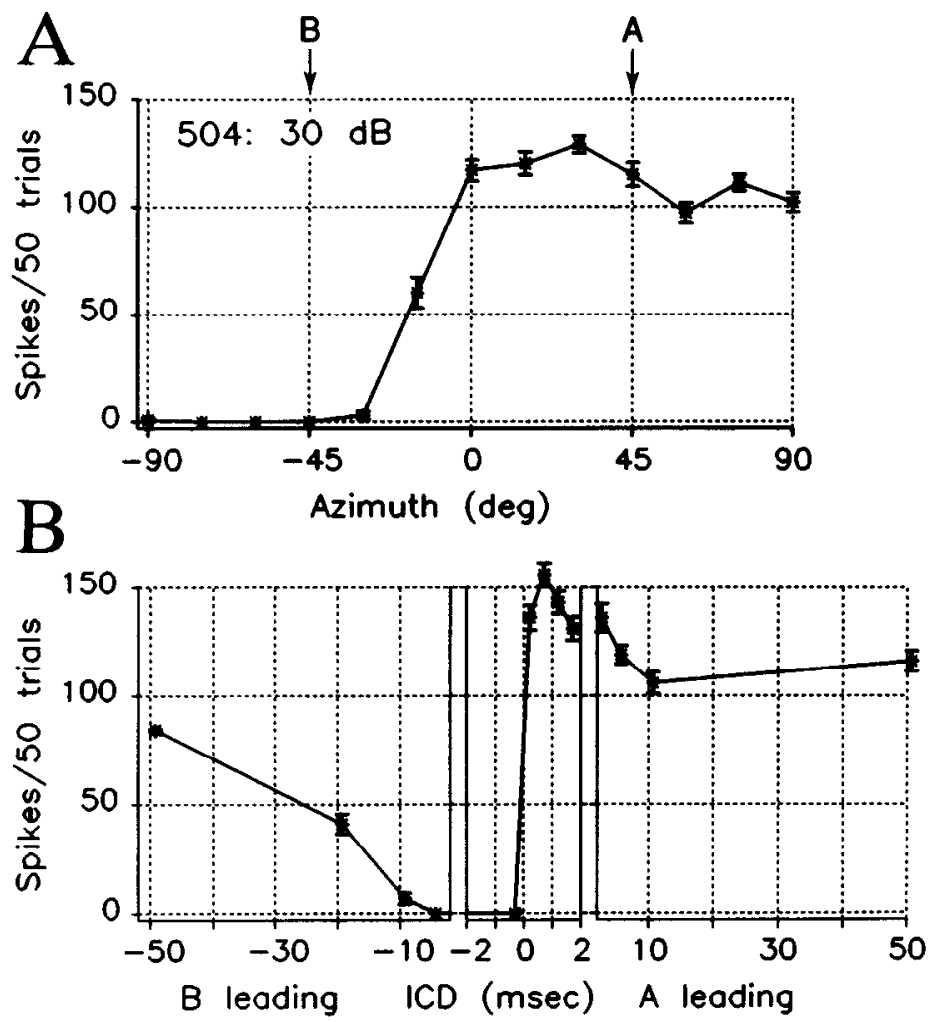

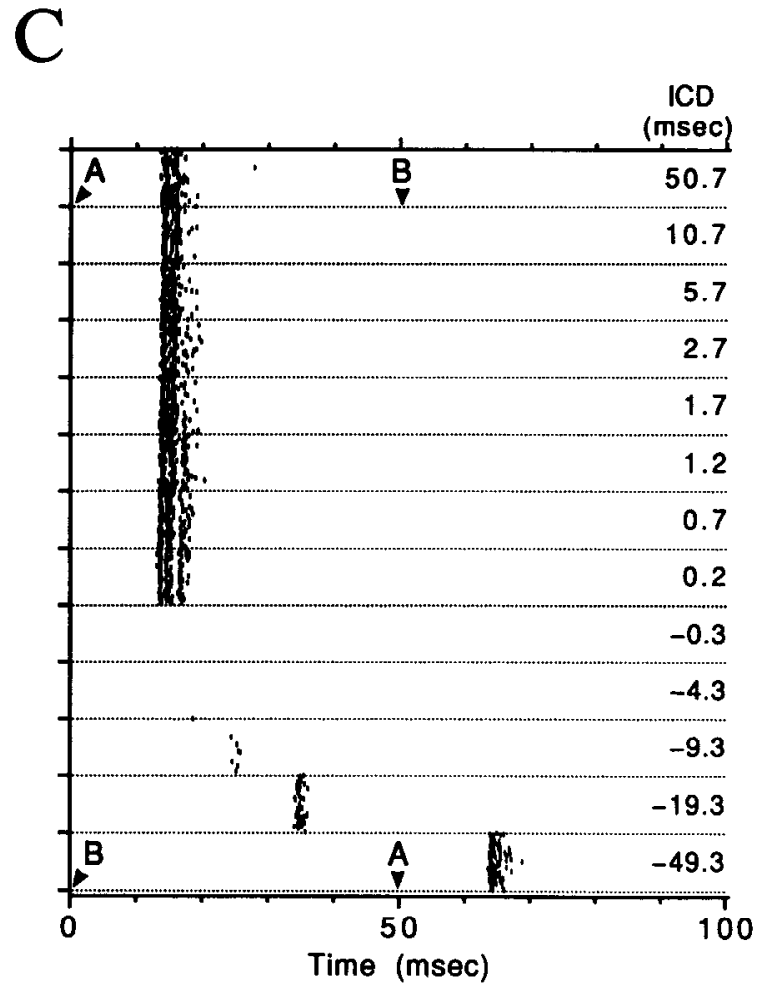

Figure 10. Responses to single clicks as a function of azimuth $(A)$ and double clicks as a function of ICD $(B, C)$ in the free field. The robust response to speaker $A$ is completely suppressed when it lags by $4 \mathrm{msec}$ or less. $\mathrm{CF}=0.6 \mathrm{kHz}$.

audiogram is predicted well by the lowest threshold fibers (Elliot et al., 1960; Liberman, 1978). If we make the assumption that the absolute echo threshold is determined by the cells with the shortest recovery curves, then there is a reasonable correlation between the half-maximal ICDs measured physiologically and the presumed psychophysical results.

Second, the physiological suppression varied with relative levels of the leading and lagging click in a manner similar to that observed behaviorally (Fig. 2). Increases in the level of the probe relative to the conditioner decrease the echo threshold, whereas decreases in the relative probe level increase the echo threshold (Blodgett et al., 1956; Thurlow and Parks, 1961; Babkoff and Sutton, 1966). The amount of change in the echo threshold for a given change in relative level is quite variable and depends upon the same factors that affect echo threshold measurements. The shifts in behavioral echo threshold with relative level are on the same order as the physiological shifts in halfmaximal suppression with relative level (Fig. 3).

Third, turning off one ear or the other under headphones, or putting the leading click in one ear and the lagging click in the other, still resulted in the physiological suppression. Although monaural stimulation was tried in only a few cells, similar results were obtained in each case; that is, the suppression seen monaurally was comparable to that evoked binaurally. Carney and Yin (1989) showed, as confirmed here for the only cell tested, that long-lasting suppression can occur with a single conditioning click to one ear and a single probe click to the opposite ear, even when the leading click does not produce a response by itself. This is consonant with psychophysical observations that the law of the first wavefront also holds when the leading and lagging clicks are delivered to different ears (Blauert, 1983; Blauert and Divenyi, 1988).
Summing localization. The correlation between the predicted response of the cells derived from their azimuthal receptive fields and their response to stimuli in the summing localization range ( $|\mathrm{ICD}|<1 \mathrm{msec})$ provided strong evidence for the link between behavior and physiology. Of particular importance were the fortuitous cases, such as that illustrated in Figure 9, where a peak in the azimuthal receptive field profile occurred between speakers $\mathrm{A}$ and $\mathrm{B}$, and the resulting ICD function also showed the peak as well as the asymmetry predicted by the receptive field profile. Moreover, these strong predictions suggest that the activity of some cells in the ICC is related to the perceived location of the sound source.

Additional support for this hypothesis also comes from the experiments in which changes in the relative level of the clicks produced changes in the response of the cell that were consonant with the expected change in perceived location at short ICDs in the summing localization range (Fig. 13). The time/intensity trading seen in the response of the cell are like those evoked behaviorally, where, for example, a decrease in the level of the leading click can be offset by an ICD introduced into the lagging click (Snow, 1954). One complication in this argument is that it rests on the unproven assumption that cats experience summing localization in a manner similar to human subjects. Behavioral experiments on trained animals will be necessary to confirm this assumption.

\section{Neural mechanisms of echo suppression}

Site of generation. While these physiological recordings have becn madc in the ICC, the sites of generation of the suppressive effects that are described here are not necessarily in that structure. Indeed, given the considerable convergence of inputs in the ICC from lower brainstem structures, there are an abundant 

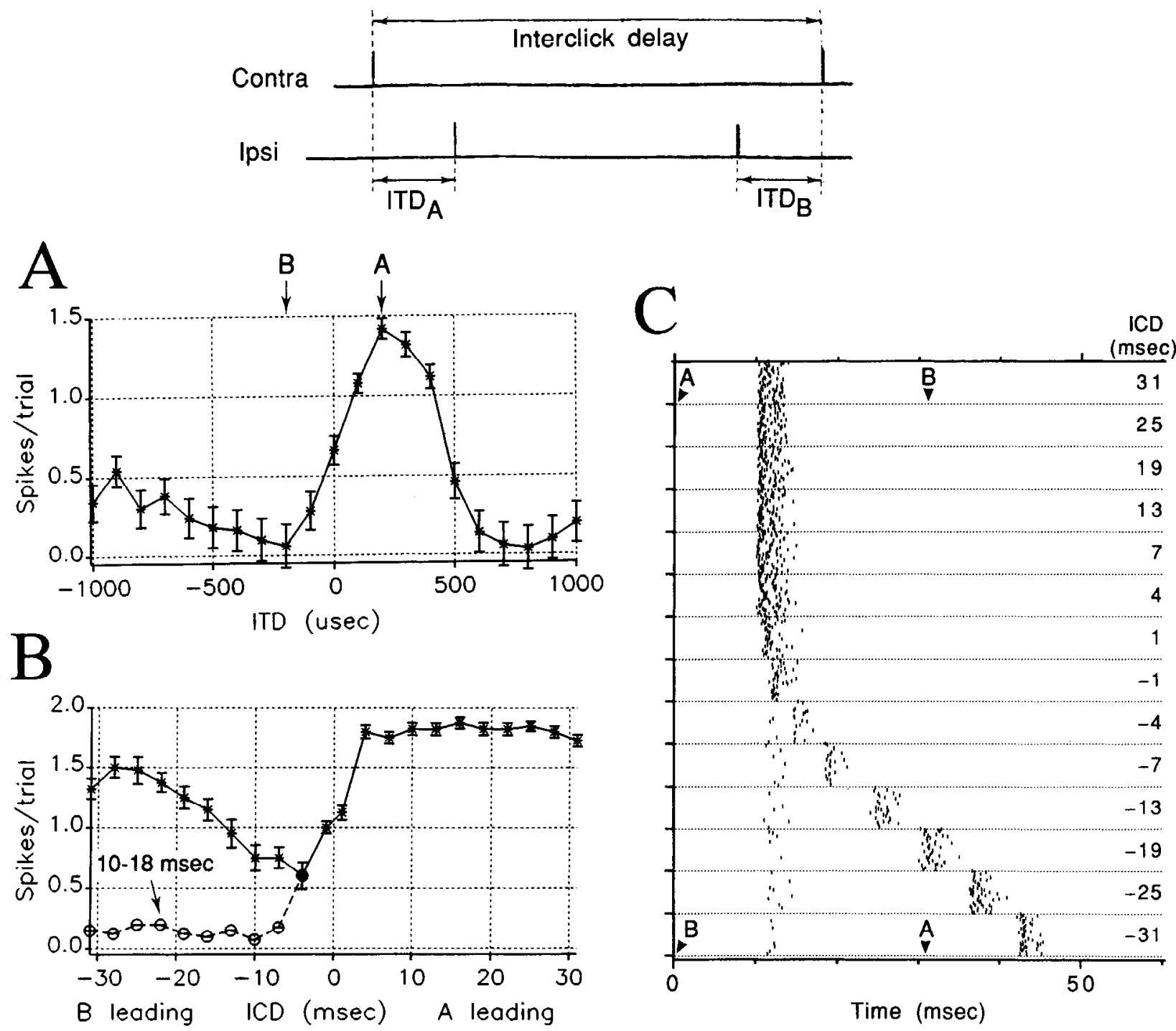

Figure 11. Responses to a single click pair as a function of ITD $(A)$ and two click pairs as a function of ICD $(B, C)$ under dichotic stimulation conditions. Stimulus configuration is shown at the top. In analogy with the terminology for free-field conditions, ITD $_{\mathrm{A}}=+200 \mu \mathrm{sec}$ and $\mathrm{ITD}_{\mathrm{B}}=$ $-200 \mu \mathrm{sec}$. $\mathrm{CF}=0.8 \mathrm{kHz}$.

number of candidate structures. I will consider here five major possible sites: the auditory nerve, cochlear nucleus, superior olivary complex (SOC), dorsal nucleus of the lateral lemniscus (DNLL), and ICC. Unfortunately, the evidence for most of these sites is inconclusive due to lack of relevant data.

There are several reasons for supposing that at least part of the suppression of the response to the lagging click is generated in the primary afferents: auditory nerve fibers are known to exhibit forward masking (Smith 1977, 1979; Harris and Dallos, 1979), as well as discharge history effects due to absolute and relative refractoriness (e.g., Gaumond et al., 1983). It is difficult to relate the present results to the masking studies, which have used CF maskers of long-duration $(100-400 \mathrm{msec})$ and shortduration CF tones as probes. Nonetheless, the time course of masking is well correlated with the short-term adaptation seen in the response to a long-duration CF tone (Harris and Dallos, 1979), which is in turn similar to the time course of the discharge history effect (Gaumond et al., 1983). This discharge history effect relates the discharge probability as a function of the time since the last spike and has been modeled as a sum of two exponentials with time constants of about 1 and $25 \mathrm{msec}$ with a fixed absolute refractory period of $0.8 \mathrm{msec}$ (Westerman and Smith, 1984, 1987). This function recovers rapidly initially, reaching $50 \%$ recovery by about $2.6 \mathrm{msec}$, and then recovers slowly so that there is about $90 \%$ recovery at $40 \mathrm{msec}$ (Gaumond et al., 1982, 1983). Direct measurements of the recovery time of auditory nerve fibers to paired clicks are, to my knowledge, not available. Our preliminary observations show that such measurements are complicated in low CF fibers by the prolonged, ringing response (Kiang et al., 1965; Goblick and Pfeiffer, 1969).

Since most cochlear nucleus cells receive convergent information from many auditory nerve (AN) fibers, the tendency for the discharge history of individual fibers to suppress the response to the probe click in a paired click stimulus can be overcome if on a given trial some AN fibers do not respond to the conditioning click. Our prcliminary observations of the responses of AN and trapezoid body fibers, that is, anteroventral cochlear nucleus (AVCN) cells, show that at moderate SPLs trapezoid body and ICC cells typically respond to every click, 

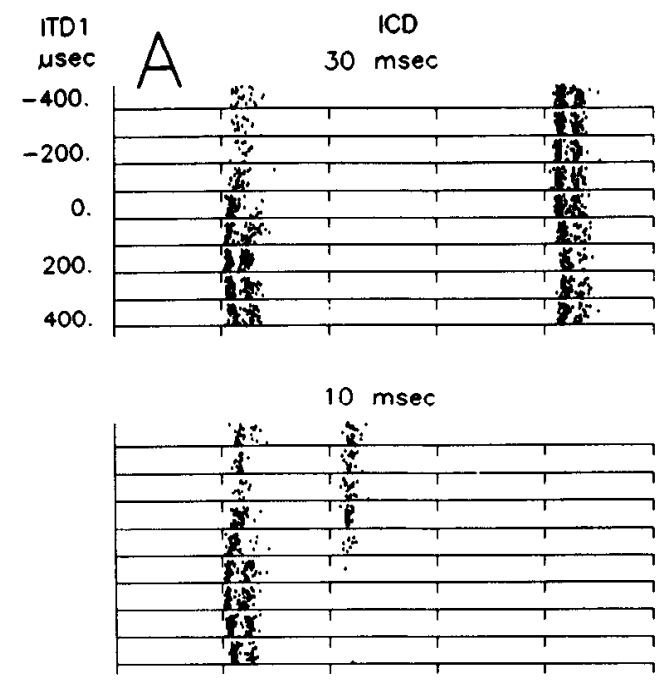

$5 \mathrm{msec}$

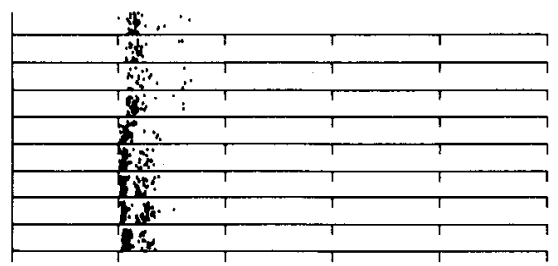

2 msec

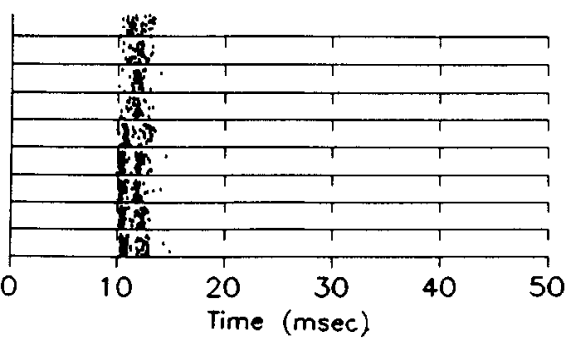

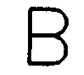

ID: $90140-4$

1TO2: $200 \mu \mathrm{sec}$

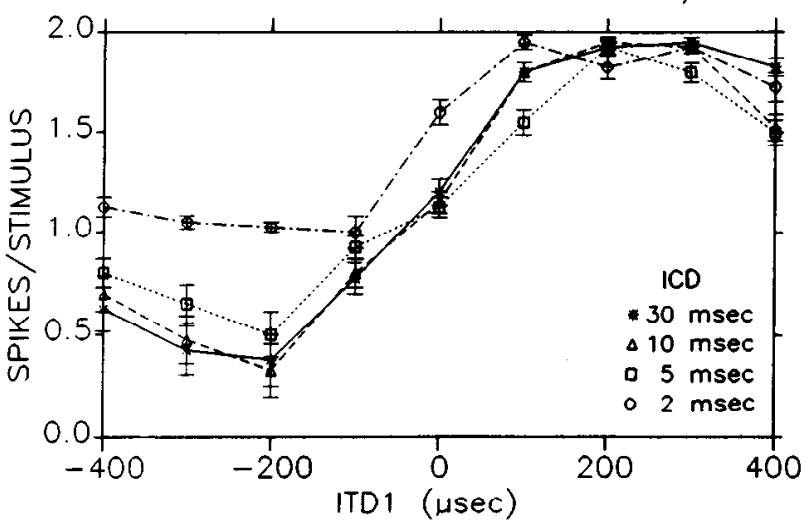

Figure 12. Responses under dichotic conditions in which ITD2 was held constant at $+200 \mu \mathrm{sec}$ and ITD1 varied from -400 to $+400 \mu$ sec at four different ICDs. $A$, Each of the four sets of dot rasters shows responses to one ICD at nine different values for ITD1. At ICD $=30$ msec, there is no suppression of the response to ITD2, while at ICD $=2 \mathrm{msec}$ the suppression is complete. $B$, Plots of the responses to the leading click for the same trials shown in $A$. Spike counts were taken over the time window of $(9,15) \mathrm{msec}$. Error bars indicate \pm 1 SEM.

whereas AN fibers tend not to do so. Thus, it seems unlikely that the adaptation of AN fibers plays a large role in the suppression seen in the ICC, at least for ICDs of greater than 2 or 3 msec.

Wickesberg and Oertel (1990) have hypothesized that monaural echo suppression may be mediated through intrinsic inhibitory circuits in the cochlear nucleus following the demonstration of putative inhibitory projections from tuberculoventral cells of the dorsal cochlear nucleus to the bushy and stellate cells of the AVCN in brain slices of mice. Preliminary tests of this hypothesis by comparisons of the responses of AVCN cells and AN fibers to paired clicks suggest some increase in the amount of suppression seen in the AVCN (Kim et al., 1992; Wickesberg, 1992; Backoff et al., 1993), but systematic comparisons are not yet available. Our own preliminary observations indicate that the half-maximal suppression in TB fibers can extend out to 2-3 msec, though in the majority of TB fibers it appears to be similar to that of AN fibers. Comparisons of forward masking in the cochlear nucleus and in AN fibers also show similarity in the shape and time course of the recovery functions for all except onset and some chopper units (Boettcher et al., 1990; Shore, 1993). In any case, there is a considerable difference between the suppression seen in the majority of ICC and AVCN cells, as the suppression in the ICC can be considerably longer than in the AVCN.

Since most cells show similar suppression when stimulated monaurally as they do binaurally, it may seem at first glance to indicate that the circuits mediating the suppression would be monaural, that is, before the site of binaural interaction, which would implicate the auditory nerve or cochlear nucleus. However, this is not necessarily the case, as can be seen from consideration of one counterexample. Suppose that the suppression is mediated by a recurrent collateral from the ICC cells under study via an inhibitory interneuron back to the same ICC cell (though I will discuss below why this is unlikely). Since most ICC cells respond to monaural stimulation of one ear or the other, the suppression would be seen under monaural as well as binaural stimulation. Thus, the presence of monaural sup- 

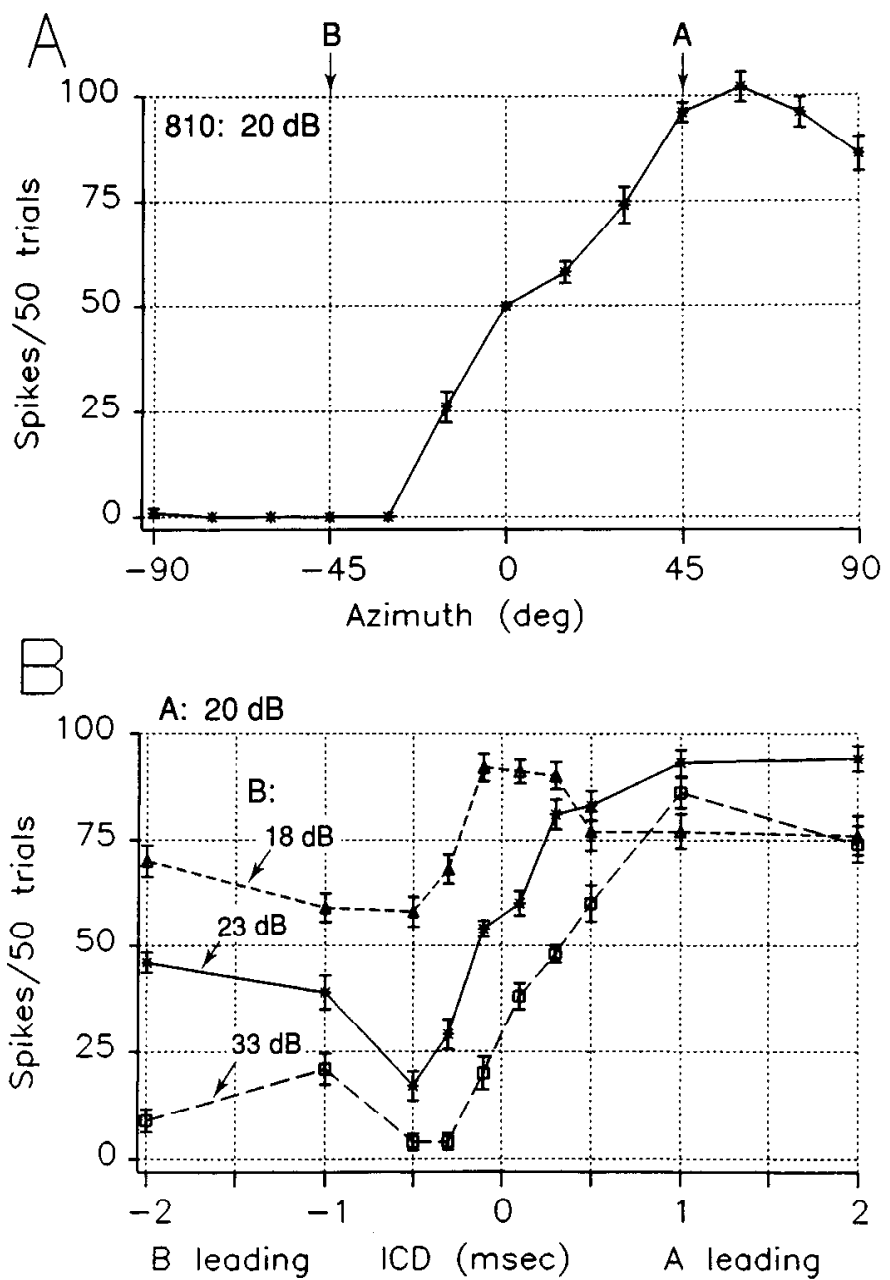

Figure 13. Effects of changing the relative level of the leading and lagging clicks on summing localization in the free field. $A$, Azimuthal sensitivity of a cell in the ICC. $B$, Responses of the cell to short ICDs at three different levels $(18,23$, and $33 \mathrm{~dB})$ of click B. Click $A$ is held at $20 \mathrm{~dB}$.

pression does not mean that the circuit that mediates the suppression is monaural.

In the superior olivary complex, the relevant data from paired clicks are not available since precedence-like stimuli have not been used. However, in a study of sensitivity of medial superior olivary (MSO) cells to ITDs of clicks, Rupert et al. (1966) and Moushegian et al. (1967) showed that stimulation of one ear can result in a long-lasting (at least $11 \mathrm{msec}$ ) suppressive effect of the response to the other ear. This suppression is similar to that seen in the ICC by Carney and Yin (1989), which triggered our interest in echo suppression. While it is the excitatory inputs to the MSO from spherical bushy cells of the AVCN of each side and their possible correspondence with the Jeffress (1948) model that has attracted the most attention (Smith et al., 1993), there is now strong anatomical and physiological evidence for inhibitory inputs to the MSO. The axonal projections of medial nucleus of the trapezoid body (MNTB) cells, which are known to project to the LSO and are thought to provide the glycinemediated inhibition from the contralateral ear, have collaterals that end in the MSO (Smith et al., 1989; Kuwubara and Zook, 1991). Cells in the lateral nucleus of the trapezoid body (LNTB), which also immunoreact with glycine antibodies and are pre- sumed inhibitory (Wenthold et al., 1987; Helfert et al., 1989), also project to the MSO (Cant and Hyson, 1992). Intracellular recordings from brainstem slices of the MSO in the guinea pig show large inhibitory postsynaptic potentials in response to electrical stimulation of the TB (Smith and Banks, 1992; Grothe and Sanes, 1993). The form and time course of the IPSPs seen in the MSO are appropriate for mediating echo suppression seen in the present study. Thus, circumstantial evidence suggests that the MSO could be the primary site of generation of the echo suppression described here.

One important aspect of the data that is not consistent with the echo suppression being generated in the AN, cochlear nucleus, or circuits leading to the MSO is the dependence of the strength of suppression on the ITD of the leading click (Fig. 12). This result implies that the inhibitory input must be dependent upon the ITD, and therefore must originate after the first stage of binaural interaction. The MNTB and LNTB, the putative sources of inhibition to the MSO, like the AN and cochlear nucleus, are predominantly monaural and, therefore, cannot mediate this effect.

Finally, we consider the possibility that the suppression is generated within the ICC itself or in the inputs to the ICC. Several examples show that the suppression may occur even when the cell does not respond to the leading click (Figs. 2, 7, $10,11)$. This observation demonstrates, at least for these cells, that the suppression is not due to fatigue or refractoriness of the ICC cell and it is not generated by an inhibitory recurrent circuit in the ICC. This does not, however, rule out the possibility that inhibitory inputs to the ICC mediate these effects.

Indeed, it seems likely that inhibitory inputs to the ICC are important. Foremost among the known inhibitory inputs to the ICC are those that arise from the dorsal nucleus of the lateral lemniscus (DNLL) (Schneiderman et al., 1988). Several aspects of the DNLL make it an attractive candidate for mediating the inhibition underlying echo suppression: cells in DNLL are binaural and scnsitive to ITDs (Brugge et al., 1970), DNLL receives input from the MSO (Glendenning et al., 1981; Henkel and Spangler, 1983), and the DNLL projects to both the ipsilateral and contralateral ICC (Schneiderman et al., 1988; Schneiderman and Oliver, 1989). Since cells that are sensitive to ITDs in the MSO respond more vigorously to delays of the ipsilateral ear (positive ITDs in our convention) and since the projection from the MSO to the DNLL is ipsilateral, we expect most cells in the DNLL to prefer positive ITDs. When the suppression varied with the ITD or azimuth of the leading click, it was always strongest when the ITD or azimuth was positive. Therefore, the ipsilateral, rather than the contralateral, DNLL would be expected to play the major role in mediating this suppression.

In considering the site of generation of echo suppression, it seems likely that all of the five sites mentioned above play a role, but with different time courses. Both the AN and cochlear nucleus show a short-lasting suppression duc to adaptive and discharge history effects and possibly intrinsic circuitry within the cochlear nucleus. More important, however, are the longerlasting effects seen in the MSO, DNLL, and ICC.

\section{Further considerations and complicating factors}

These data were collected from deeply anesthetized cats. It is likely that the anesthetic state of the animal will influence some of the results shown here. For example, it is known that sodium pentobarbital potentiates the effect of inhibitory processes in the CNS (Barker and Ransom, 1978; Kuwada et al., 1989). Thus, 
I would expect that cells in the normal, unanesthetized cat would show less echo suppression. This may also account for the lower half-maximal ICDs reported here as compared with the behavioral echo thresholds.

Another factor that was not explored systematically in these experiments is the influence of the overall level of the stimulus. In summing localization, the perceived level of the sound is increased relative to the single click condition (Thurlow and Parks, 1961). The enhanced level gradually decreases as the ICDs are lengthened to reach the echo threshold. Such changes in perceived level were not taken into account in our preliminary analysis since there is no simple correspondence between the level enhancement and ICD.

Several recent psychophysical studies have shown that the PE is a dynamic process, and therefore one that might not have a simple physiological correlate. Saberi and Perrott (1990) showed a strong effect of prior practice on the perception of the PE; subjects that had undergone considerable practice in listening to paired clicks could more readily detect the second click, even when the ICDs were such that echo suppression would be expected to be potent. Clifton (1987) found that an abrupt switch in the sign of the ICD in the midst of a pulse train results in a momentary "breakdown" of echo suppression, and Freyman et al. (1991) found that echo suppression increases in strength during a train of click pairs, which they term "buildup." While I did not test for the presence of such effects by exactly mimicking the stimulus conditions, I did not see any evidence for buildup with successive stimulus repetitions in recordings from the ICC of the anesthetized cat. Such complex interactions may be mediated by cortical or higher-order processing in the nervous system.

\section{References}

Aitkin LM, Pettigrew JD, Calford MB, Phillips SC, Wise LZ (1985) Representation of stimulus azimuth by low-frequency neurons in inferior colliculus of the cat. J Neurophysiol 53:43-59.

Babkoff H, Sutton S (1966) End point of lateralization for dichotic clicks. J Acoust Soc Am 39:87-102.

Backoff PM, Boettcher F, Caspary DM (1993) Response suppression in a paired-click masking paradigm in chinchilla cochlear nucleus: a possible role of local inhibition. Assoc Res Otolaryngol Abstr 16:39.

Barker JL, Ransom BR (1978) Pentobarbitone pharmacology of mammalian central neurones grown in tissue culture. J Physiol (Lond) 280: 355-372.

Blauert J (1983) Spatial hearing. The psychophysics of human sound localization. Cambridge, MA: MIT Press.

Blauert J, Divenyi PL (1988) Spectral selectivity in binaural contralateral inhibition. Acustica 66:267-274.

Blodgett HC, Wilbanks WA, Jeffress LA (1956) Effect of large interaural time differences upon the judgement of sidedness. J Acoust Soc Am 28:639-643.

Boettcher FA, Salvi RJ, Saunders SS (1990) Recovery from shortterm adaptation in single neurons in the cochlear nucleus. Hear Res 48:125-144.

Brugge JF, Anderson DJ, Aitkin LM (1970) Responses of neurons in the dorsal nucleus of the lateral lemniscus of the cat to binaural tonal stimulation. J Neurophysiol 33:441-458.

Cant NB, Hyson RL (1992) Projections from the lateral nucleus of the trapezoid body to the medial superior olivary nucleus in the gerbil. Hear Res 58:26-34.

Carney LH, Yin TCT (1989) Responses of low-frequency cells in the inferior colliculus to interaural time differences of clicks: excitatory and inhibitory components. J Neurophysiol 62:144-161.

Clifton RK (1987) Breakdown of echo suppression in the precedence effect. J Acoust Soc Am 82:1834-1835.

Cranford JL (1982) Localization of paired sound sources in cats: effects of variable arrival times. J Acoust Soc Am 72:1309-1311.

Cranford JL, Oberholtzer M (1976) Role of neocortex in binaural hearing in the cat. II. The "precedence" effect in sound localization. Brain Res 111:225-239.

Cranford J, Ravizza R, Diamond IT, Whitfield IC (1971) Unilateral ablation of the auditory cortex in the cat impairs complex sound localization. Science 172:286-288.

Elliott DN, Stein L, Harrison MJ (1960) Discrimination of absoluteintensity thresholds and frequency-difference thresholds in cats. $\mathrm{J}$ Acoust Soc Am 32:380-384.

Freyman RL, Clifton RK, Litovsky RY (1991) Dynamic processes in the precedence effect. J Acoust Soc Am 90:874-884.

Gaskell H (1983) The precedence effect. Hear Res 11:277-303.

Gaumond RP, Molnar CE, Kim DO (1982) Stimulus and recovery dependence of cat cochlear nerve fiber spike discharge probability. J Neurophysiol 48:856-873.

Gaumond RP, Kim DO, Molnar CE (1983) Response of cochlear nerve fibers to brief acoustic stimuli: role of discharge-history effects. J Acoust Soc Am 74:1392-1398.

Glendenning KK, Brunso-Bechtold JK, Thompson GC, Masterton RB (1981) Ascending auditory afferents to the nuclei of the lateral lemniscus. J Comp Neurol 197:673-703.

Goblick TJ, Pfeiffer RR (1969) Time domain measurements of cochlear nonlinearities using combination click stimuli. J Acoust Soc Am 46:924-938.

Green DM (1976) An introduction to hearing. Hillsdale, NJ: Erlbaum.

Grothe B, Sanes DH (1993) Bilateral inhibition by glycinergic afferents in the medial superior olive. J Neurophysiol 69:1192-1196.

Haas $H$ (1951) The influence of a single echo on the audibility of speech. Acoustica 1:49-58.

Harris DM, Dallos P (1979) Forward masking of auditory nerve fiber responses. J Neurophysiol 42:1083-1107.

Hartmann WM (1983) Localization of sound in rooms. J Acoust Soc Am 74:1380-1391.

Helfert RH, Bonneau JM, Wenthold RJ, Altschuler RA (1989) GABA and glycine immunoreactivity in the guinea pig superior olivary complex. Brain Res 501:269-286.

Henkel CK, Spangler KM (1983) Organization of the efferent projections of the medial superior olivary nucleus in the cat as revealed by HRP and autoradiographic tracing methods. J Comp Neurol 221 : 416-428.

Irvine DRF, Gago G (1990) Binaural interaction in high frequency neurons in inferior colliculus of the cat. J Neurophysiol 63:570-591.

Jeffress LA (1948) A place theory of sound localization. J Comp Physiol Psychol 41:35-39.

Kelly JB (1974) Localization of paired sound sources in the rat: small time differences. J Acoust Soc Am 55:1277-1284.

Kiang NYS, Watanabe T, Thomas EC, Clark LF (1965) Discharge pattern of single fibers in the cat auditory nerve. Cambridge, MA: MIT Press.

Kim DO, Parham K, Tracy T (1992) Responses of auditory nerve (AN) fibers and anteroventral cochlear nucleus (AVCN) units to click pairs in unanesthetized decerebrate cats. Assoc Res Otolaryngol Abstr 15:60.

Kuwabara N, Zook JM (1991) Classification of the principal cells of the medial nucleus of the trapezoid body. J Comp Neurol 314:707720.

Kuwada S, Yin TCT (1983) Binaural interaction in low-frequency neurons in inferior colliculus of the cat. I. Effects of long interaural delays, intensity, and repetition rate on interaural delay function. $J$ Neurophysiol 50:981-999.

Kuwada S, Batra R, Stanford TR (1989) Monaural and binaural response properties of neurons in the inferior colliculus of the rabbit: effects of sodium pentobarbital. J Neurophysiol 61:269-282.

Liberman MC (1978) Auditory-nerve response from cats raised in a low-noise chamber. J Acoust Soc Am 63:442-455.

Lindemann W (1986) Extension of a binaural cross-correlation model by contralateral inhibition. Part II: the law of the first wave front. J Acoust Soc Am 80:1623-1630.

Litovsky RY, Macmillan NA (1993) Sound localization precision under conditions of the precedence effect: effects of azimuth and standard stimuli. J Acoust Soc Am, in press.

Moushegian G, Rupert AL, Langford TL (1967) Stimulus coding by medial superior olivary neurons. J Neurophysiol 30:1239-1261.

Perrott DR, Strybel TZ, Manligas CL (1987) Conditions under which the Haas precedence effect may or may not occur. J Aud Res 27:5972. 
Perrott DR, Marlborough K, Merrill P, Strybel TZ (1989) Minimum audible angle thresholds obtained under conditions in which the precedence effect is assumed to operate. $\mathrm{J}$ Acoust Soc Am 85:282-288.

Rose JE, Gross NB, Geisler CD, Hind JE (1966) Some neural mechanisms in the inferior colliculus of the cat which may be relevant to localization of a sound source. J Neurophysiol 29:288-314.

Rupert A, Moushegian G, Whitcomb MA (1966) Superior-olivary response patterns to monaural and binaural clicks. J Acoust Soc Am 39:1069-1076.

Saberi K, Perrott DR (1990) Lateralization thresholds obtained under conditions in which the precedence effect is assumed to operate. J Acoust Soc Am 87:1732-1737.

Schneiderman A, Oliver DL (1989) An FM autoradiographic study of the projections from the dorsal nucleus of the lateral lemniscus. A possible source of inhibitory inputs to the inferior colliculus. J Comp Neurol 286:28-47.

Schneiderman A, Oliver DL, Henkel CK (1988) The connections of the dorsal nucleus of the lateral lemniscus. An inhibitory parallel pathway in the ascending auditory system? J Comp Neurol 276:188208.

Semple MN, Kitzes LM (1987) Binaural processing of sound pressure level in the inferior colliculus. J Neurophysiol 57:1130-1 147.

Shinn-Cunningham BG, Zurek PM, Durlach NI (1993) Adjustment and discrimination measurements of the precedence effect. J Acoust Soc Am 93:2923-2932.

Shore SE (1993) Forward masking in cochlear nucleus neurons: masker level and spontaneous-rate effects. Assoc Res Otolaryngol Abstr 16: 40.

Smith PH, Banks MI (1992) Intracellular recordings from neurobiotinlabeled principal cells in brain slices of the guinea pig MSO. Soc Neurosci Abstr 18:382.

Smith PH, Joris PX, Banks MI, Yin TCT (1989) Physiology and anatomy of principal cells in the cat MNTB. Soc Neurosci Abstr 15: 746.

Smith PH, Joris PX, Yin TCT (1993) Projections of physiologically characterized spherical bushy cell axons from the cochlear nucleus of cat: evidence for delay lines to the medial superior olive. J Comp Neurol 331:245-260.

Smith RL (1977) Short-term adaptation in single auditory nerve fibers: some post stimulatory effects. J Neurophysiol 40:1098-1112.
Smith RL (1979) Adaptation, saturation, and physiological masking in single auditory-nerve fibers. J Acoust Soc Am 65:166-178.

Snow WB (1954) Effect of arrival time on stereophonic localization. J Acoust Soc Am 26:1071-1074.

Thurlow WR, Parks TE (1961) Precedence-suppression effects for two click sources. Percept Mot Skills 13:7-12.

Wallach H, Newman EB, Rosenzweig MR (1949) The precedence effect in sound localization. Am J Psychol 57:315-336.

Wenthold RJ, Huie D, Altschuler RA, Reeks KA (1987) Glycine immunoreactivity localized in the cochlear nucleus and superior olivary complex. Neuroscience 22:897-912.

Westerman LA, Smith RL (1984) Rapid and short-term adaptation in auditory nerve responses. Hear Res 15:249-260.

Westerman LA, Smith RL (1987) Conservation of adapting components in auditory-nerve responses. J Acoust Soc Am 81:680-691.

Whitfield IC, Cranford J, Ravizza R, Diamond IT (1972) Effects of unilateral ablation of auditory cortex in cat on complex sound localization. J Neurophysiol 35:718-731.

Wickesberg RE (1992) Suppression of a trailing click in responses of neurons in the cochlear nuclear complex of the rat. Assoc Res Otolaryngol Abstr 15:60.

Wickesberg RE, Oertel D (1990) Delayed, frequency-specific inhibition in the cochlear nuclei of mice: a mechanism for monaural echo suppression. J Neurosci 10:1762-1768.

Wyttenbach RA, Hoy RR (1993) Demonstration of the precedence effect in an insect. J Acoust Soc Am 94:777-784.

Yin TCT, Chan JCK, Irvine DRF (1986) Effects of interaural time delays of noise stimuli on low-frequency cells in the cat's inferior colliculus. I. Responses to wide-band noise. J Neurophysiol 55:280300.

Yin TCT, Chan JCK, Carney LH (1987) Effects of interaural time delays of noise stimuli on low-frequency cells in the cat's inferior colliculus. III. Evidence for cross-correlation. J Neurophysiol 58:562583.

Yost WA, Soderquist DR (1984) The precedence effect: revisited. J Acoust Soc Am 76:1377-1383.

Zurek PM (1980) The precedence effect and its possible role in the avoidance of interaural ambiguities. J Acoust Soc Am 67:952-964.

Zurek PM (1987) The precedence effect. In: Directional hearing (Yost WA, Gourevitch G, eds), pp 85-105. New York: Springer. 